Review

\title{
Emerging roles of SIRT1 in fatty liver diseases
}

\author{
Ren-Bo Ding, Jiaolin Bao, Chu-Xia Deng ${ }^{\bowtie}$ \\ Cancer Centre, Faculty of Health Sciences, University of Macau, Macau SAR 999078, China \\ $\triangle$ Corresponding author: Chu-Xia Deng, Faculty of Health Sciences, University of Macau, Macau SAR 999078, China. cxdeng@umac.mo \\ (C) Ivyspring International Publisher. This is an open access article distributed under the terms of the Creative Commons Attribution (CC BY-NC) license \\ (https://creativecommons.org/licenses/by-nc/4.0/). See http://ivyspring.com/terms for full terms and conditions.
}

Received: 2017.01.27; Accepted: 2017.04.19; Published: 2017.07.06

\begin{abstract}
Fatty liver diseases, which are commonly associated with high-fat/calorie diet, heavy alcohol consumption and/or other metabolic disorder causes, lead to serious medical concerns worldwide in recent years. It has been demonstrated that metabolic homeostasis disruption is most likely to be responsible for this global epidemic. Sirtuins are a group of conserved nicotinamide adenine dinucleotide $\left(\mathrm{NAD}^{+}\right)$dependent histone and/or protein deacetylases belonging to the silent information regulator 2 (Sir2) family. Among seven mammalian sirtuins, sirtuin 1 (SIRT 1) is the most extensively studied one and is involved in both alcoholic and nonalcoholic fatty liver diseases. SIRTI plays beneficial roles in regulating hepatic lipid metabolism, controlling hepatic oxidative stress and mediating hepatic inflammation through deacetylating some transcriptional regulators against the progression of fatty liver diseases. Here we summarize the latest advances of the biological roles of SIRT1 in regulating lipid metabolism, oxidative stress and inflammation in the liver, and discuss the potential of SIRT1 as a therapeutic target for treating alcoholic and nonalcoholic fatty liver diseases.
\end{abstract}

Key words: fatty liver diseases; lipogenesis; fatty acid $\beta$-oxidation; oxidative stress; inflammation.

\section{Introduction}

The prevalence of fatty liver diseases in developed countries has increased dramatically and becomes a serious health problem. Non-alcoholic fatty liver diseases (NAFLD) has prevalence as high as $20-40 \%$ in general population and accounts for $75 \%$ incidence of obesity or diabetes in Western countries [1]. In UK, alcohol-related liver diseases is responsible for over a third $(37 \%)$ of deaths associated with liver diseases [2]. Metabolic homeostasis disruption is mostly likely to be responsible for this global epidemic of fatty liver diseases, and most cases of fatty liver diseases are commonly associated with metabolic syndromes, such as hyperlipidemia and insulin resistance, and are frequently linked with other metabolic diseases like obesity and type 2 diabetes mellitus [3]. In clinical practice, fatty liver diseases encompass a continued spectrum of liver damage, which progresses from simple hepatic steatosis to advanced steatohepatitis, and in some cases, even to fibrosis, cirrhosis, and hepatocellular carcinoma $[4,5]$.
In recent years, accumulating evidences indicate that sirtuins play important roles in regulating the fatty liver diseases related metabolic processes. Sirtuins are a group of highly conserved $\mathrm{NAD}^{+}$ dependent histone and protein deacetylases and/or ADP-ribosyl transferases that play important functions in numerous biological processes [6-17]. Sirtuins are named because of their homology to Saccharomyces cerevisiae gene silent information regulation-2 (Sir2) and grouped as class III histone deacetylases (HDACs) [18, 19]. To date, there are seven mammalian homolegs of sirtuin (SIRT1-7) have been reported, which are located in different subcellular regions, i.e. the nucleus (SIRT1, 2, 6 and 7), the cytoplasm (SIRT1 and 2), and the mitochondria (SIRT3, 4 and 5) [20]. While several members of sirtuin family are implicated in various aspects of fatty liver [21-26], SIRT1 is the most extensively studied member, and is involved in both NAFLD and alcoholic fatty liver diseases (AFLD) [22, 27-32]. In this review, we will summarize the latest advances about 
roles of SIRT1 in fatty liver diseases, with a focus on how SIRT1 regulates lipid metabolism, oxidative stress and inflammation in the liver. We will also discuss the potential applications of SIRT1 activators as therapeutic agents for fatty liver diseases treatment.

\section{Pathology of fatty liver diseases}

The main reasons causing fatty liver diseases are due to the popular high-fat/calorie diet or heavy alcohol intake, which lead to NAFLD or AFLD respectively $[4,6,33,34]$. The initial early stage of fatty liver diseases is hepatic steatosis, which is characterized by excessive triglyceride (TG) deposition as lipid droplets in hepatocytes [35]. Abnormal cytoplasmic lipid accumulation in the liver is primarily caused by imbalance of hepatic lipid homeostasis between TG/fatty acids acquisition and removal, which involves increased fatty acids/TG uptake, enhanced de novo lipogenesis, impaired fatty acids $\beta$-oxidation, and/or decreased lipid export as the form of very low-density lipoprotein (VLDL) in liver $[4,35,36]$.

Hepatic TG acquisition is generally derived from three sources, including diet, de novo synthesis and adipose tissue. Under high-fat diet, dietary fats taken up in the intestine are delivered into blood circulation as TG-rich chylomicrons and free fatty acids (FFA), and about $20 \%$ of them are delivered into the liver by hepatic lipid uptake [35, 37]. Under high-calorie diet, carbohydrate intake increases circulating glucose and insulin levels, further promotes de novo lipogenesis from acetyl-coenzyme A (CoA) through activating transcription factor carbohydrate response element binding protein (ChREBP) and sterol regulatory element binding protein-1c (SREBP-1c) $[38,39]$. With heavy alcohol intake regardless of long-term or short-term, lipolysis in white adipose tissue is stimulated through activating the lipases, adipose triglyceride lipase (ATGL) and hormone sensitive lipase (HSL), to release FFA into the circulation, meanwhile hepatic fatty acids (FA) uptake capability is also evaluated through overexpressing FA-transport proteins, including fatty acid translocase 36 (CD36) and fatty acid transporter proteins (FATPs) [40-42]. In addition, alcohol exposure and high-fat diet could promote hepatic de novo lipogenesis as well [36, 43]. Acquired FFA in liver has three possible fates, as shown in figure 1 . It can be metabolized by $\beta$-oxidation in mitochondria to produce energy and ketone bodies mainly through peroxisome proliferator-activated receptor alpha (PPARa) and peroxisome proliferator-activated receptor-gamma co-activator 1 alpha (PGC-1a) signaling regulation, esterified to TG and stored in lipid droplets, or packaged with apolipoprotein B (ApoB) and secreted into blood circulation as the form of VLDL [35]. The imbalance of hepatic TG/fatty acids flux acquisition and removal consequently causes steatosis in the liver (Figure 1).

Clinically, fatty liver diseases always encompass a continued spectrum of liver damages: benign hepatic steatosis, steatohepatitis, fibrosis, cirrhosis, and end-stage liver diseases $[4,5]$. For NAFLD only, about one-third of NAFLD patients who undergo histological biopsy have the evidence of steatohepatitis, of whom, $10 \%$ to $30 \%$ progress to fibrosis and cirrhosis within 10 years [44, 45]. In addition to acting as the first hit to induce steatosis, accumulated large amounts of lipid droplets in the liver also trigger mitochondrial oxidative stress characterized by abundant reactive oxygen species (ROS) production, and hepatic inflammation with large cytokine production, particularly tumor necrosis factor a (TNF-a) and interleukin 6 (IL-6), which are considered as critical factors or hits leading to the progression from simple steatosis to advanced steatohepatitis or even fibrosis and cirrhosis [4, 46-48]. In addition, the hepatic inflammation is also contributed by circulating cytokines secreted from adipose tissue, and both high-fat/calorie diet and heavy alcohol intake are able to trigger significant inflammation in adipose tissue [49-52]. As summarized in figure 1 \& 2, aberrant lipid metabolism and accumulated oxidative stress/inflammation levels are important factors that promote TG deposition in the liver and the progression of fatty liver diseases from steatosis to advanced stage.

\section{Mammalian SIRT1}

SIRT1 functions by cleaving the nicotinamideribosyl bond of $\mathrm{NAD}^{+}$and transfering the acetyl group from the substrate's lysine side chain to $\mathrm{NAD}^{+}$, thereby generating nicotinamide, 2'-O-acetyl-ADP-ribose and a deacetylated substrate [53-55]. As NAD ${ }^{+}$is required as a co-substrate in this process, SIRT1 activity can be activated by increasing intracellular $\mathrm{NAD}^{+}$levels, and inhibited by high nicotinamide levels [56]. Increasing evidences demonstrated that SIRT1 acts as a key metabolic/energy sensor, which directly couples the cellular metabolic/energy status (via intracellular $\mathrm{NAD}^{+} / \mathrm{NADH}$ ratio) to transcriptional activity and/or gene expression of several crucial transcription factor and transcription co-activators that are involved in metabolic homeostasis $[6,18,55$, 57, 58]. These includes ChREBP, SREBP-1c, peroxisome proliferator-activated receptor alpha (PPARa), peroxisome proliferator-activated 
receptor-gamma co-activator 1 alpha (PGC-1a), nuclear factor-kB (NF-kB) and so on.

Of note, it is known that some factors, such as alcohol, high-fat diet, and high-calorie diet, could impair functions of SIRT1. The mechanisms underlying how these factors affect SIRT1 are complex, and may involved multiple ways. But experimental evidence indicates that one of the major factors is $\mathrm{NAD}^{+}$, which affects SIRT1 activity. In this regards, it was reported that alcohol consumption could result in decreased $\mathrm{NAD}^{+} / \mathrm{NADH}$ ratio as well as SIRT1 activity in hepatocytes [31, 59]. During alcohol metabolism, alcohol is firstly metabolized by either alcohol dehydrogenase (ADH) in the cytosol or cytochrome P450 IIE1 (CYP2E1) in the endoplasmic reticulum to produce acetaldehyde, which is further rapidly metabolized by mitochondrial aldehyde dehydrogenase (ALDH2) to form acetate and convert $\mathrm{NAD}^{+}$to NADH $[60,61]$. Moreover, reduced NAD ${ }^{+}$ level and SIRT1 activity were concomitant with dietary energy/nutrition overload status such as high-fat diet and/or high-calorie diet feeding conditions [62-64], whereas calorie restriction could increase $\mathrm{NAD}^{+}$level and induce SIRT1 activation [65, 66]. Besides affecting $\mathrm{NAD}^{+}$level, it was also recently observed that aging could aggravate alcoholic liver diseases through down-regulating SIRT1 protein although the underlying mechanism remains elusive [59]. Given the $\mathrm{NAD}^{+}$dependency of SIRT1, SIRT1 therefore servers as important metabolic sensor, which couples alcohol, high-fat diet and high-calorie diet intake with corresponding lipid/energy homeostasis signaling in the liver and other associated organs.

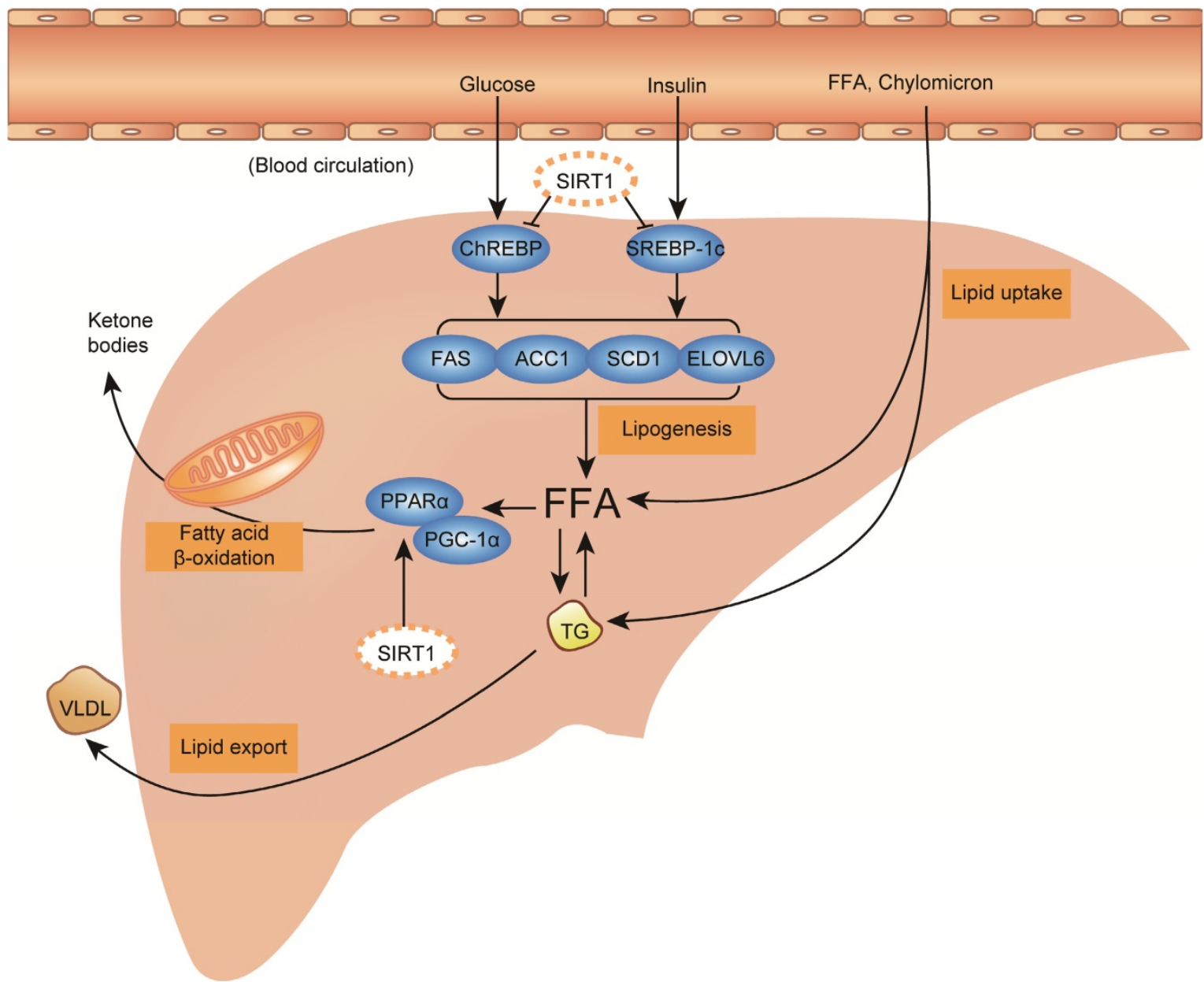

Figure 1. Fatty liver diseases are initiated by aberrant hepatic lipid metabolism, and sirtuin 1 (SIRT1) activation plays beneficial effect against the process through inhibiting de novo lipogenesis and increasing fatty acid $\beta$-oxidation. Liver steatosis is the initial stage of fatty liver diseases, which is characterized by excessive triglyceride (TG) deposition as lipid droplets in the liver. Lipid metabolism is tightly linked with dietary fat, calorie and alcohol intake, which could be subsequently digested and convert to circulating TG-rich chylomicrons, free fatty acid (FFA), glucose, insulin and so on. Circulating TG-rich chylomicrons and free fatty acid (FFA) could be uptaken by liver through transmembrane proteins. High levels of circulating glucose and insulin could stimulate de novo lipogenesis activating transcription factors carbohydrate response element binding protein (ChREBP) and sterol regulatory element binding protein- $1 \mathrm{c}$ (SREBP-1c), followed by activating their downstream lipogenic enzymes including fatty acid synthase (FAS), acetyl-CoA carboxylase 1 (ACC1), stearoyl-CoA desaturase-1 (SCDI) and elongase of long chain fatty acids family 6 (ELOVL6) to synthesize FFA and TG in the liver. In order to maintain lipid homeostasis, there are also two removal pathways for acquired FFA and TG, including metabolizing FFA through fatty acid $\beta$-oxidation in mitochondria via peroxisome proliferator-activated receptor alpha (PPARa) / peroxisome proliferator-activated receptor-gamma co-activator 1 alpha (PGC-1 $\alpha$ ) signaling, and secreting TG into blood circulation as the form of very low-density lipoprotein (VLDL). Under high-fat diet, high-calorie diet and/or heavy alcohol intake condition, excessive lipid acquisition usually is stimulated through increasing lipid uptake and/or lipogenesis, meanwhile lipid removal pathway could also be impaired by decreasing fatty acid $\beta$-oxidation and/or VLDL secretion. Together, the imbalance of hepatic TG/fatty acids flux acquisition and removal consequently cause steatosis in the liver. During the process, SIRTI activation shows beneficial effect through inhibiting lipogenesis by deacetylating SREBP-1c and ChREBP to block their downstream lipogenic genes, and increasing fatty acid $\beta$-oxidation via deacetylating PPARa/PGC-1 $\alpha$, thus rebalances the hepatic lipid hemostasis. 


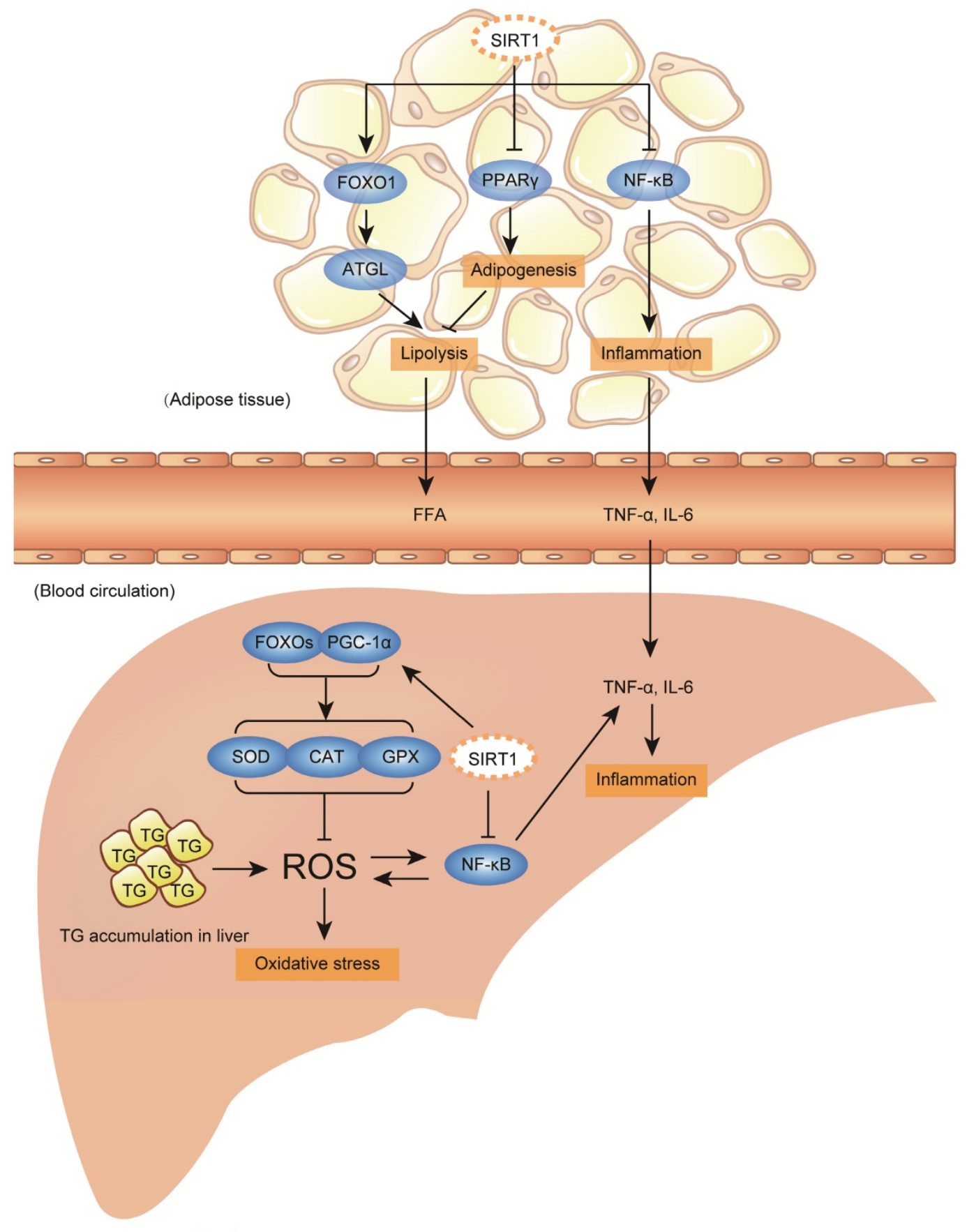

(Liver)

Figure 2. Accumulated hepatic oxidative stress and inflammation promote fatty liver diseases progression, and SIRTI activation plays beneficial effect against diseases progression. Accumulated lipid droplets in the liver will trigger further hepatic oxidative and inflammation, which subsequently develop a continued liver damage process. The excessive hepatic oxidative stress and inflammation are characterized by abundant reactive oxygen species (ROS) production and large cytokine production, particularly tumor necrosis factor $\alpha$ (TNF- $\alpha$ ) and interleukin 6 (IL-6). Additionally, adipose tissue also contributes to the diseases aggravation by secreting FFA and inflammatory cytokines to circulation, which further could be delivered to liver. During fatty liver diseases progression, SIRTI activation plays beneficial roles on defending hepatic oxidative stress through enhancing antioxidant capability involving fork head box proteins (FOXOs) and PGC-1 $\alpha$ deacetylation, and reducing pro-inflammatory cytokines production through deacetylating nuclear factor-KB (NF-KB) both in the liver and in the adipose tissue. In addition to beneficial effect, SIRTI activation also possesses a contradictory role in adipose tissue-liver axis, which might exacerbate fatty liver formation. Under SIRTI activation, transcriptional activity of peroxisome proliferator-activated receptor gamma (PPARY) is repressed and FOXOI/ adipose triglyceride lipase (ATGL) signaling is activated, which promote lipolysis of adipose tissue to increase large amount of FFA fluxing to circulation, later might be uptaken by liver.

\section{Role of SIRT1 in fatty liver diseases: phenotype of SIRT1 deficient and transgenic mice}

The function of SIRT1 in fatty liver formation was first studied in mice with an albumin-Cre (Alb-Cre) mediated liver-specific deletion of exon 4 of the Sirt1 gene [28, 67]. The mutant mice (Sirt1flox4fflox4;Alb-Cre) had no obvious abnormality under regular feeding condition, however, displayed either attenuated [67] or accelerated [28] hepatic 
steatosis when they were fed with high-fat diet. While this discrepancy is not clear, Wang et al. generated and studied mice carrying liver-specific deletion of exons 5 and 6 of Sirt1 gene mediated by Alb-Cre (Sirt1 flox5-6/flox5-6; Alb-Cre, or Sirt1LKO) [68]. The data indicate that as early as 2 months, $28.6 \%(2 / 7)$ of Sirt1 ${ }^{\mathrm{LKO}}$ mice have started to accumulate lipid droplet (Figure 3A). At 6 months, 55.9\% (5/9) of them have developed fatty liver. The frequency of fatty liver is increased to $77.8 \%$ (7/9) when the Sirt1 ${ }^{\mathrm{LKO}}$ mice at 14 months age, whereas only $16.6 \%(2 / 12)$ control mice suffered fatty liver during the same time (Figure 3A, B). Consistent with the increased lipid deposition, significant higher TG content level in liver and plasma are also observed in mutant mice than in controls (Figure 3C, E), plasma FFA level also increased in mutant mice compared to controls but without significance (Figure 3D). These data provide the direct evidences that SIRT1 deficiency in the liver induce fatty liver diseases even without high-fat diet. Accompanied with hepatic steatosis development, the Sirt1 ${ }^{\text {LKO }}$ mice also exhibited hyperglycemia and insulin resistance due to increased hepatic gluconeogenesis, and are associated with increased intracellular ROS accumulation in multiple tissues, including liver, adipose tissue, skeletal muscle and spleen [69]. These data indicate that liver specific disruption of SIRT1 not only causes hepatic steatosis but also promotes the progression to advanced metabolic disorder stage. A recent study on human fetal hepatocytes treated with sirtinol, a pharmacological inhibitor of SIRT1, confirmed the finding from Sirt1LKO mice about lipid and glucose accumulation in hepatocytes induced by SIRT1 deficiency [70].

A recent study also showed that Sirt $1^{\text {flox4/flox4; }}$ Alb-Cre mice challenged with alcohol-containing diet exacerbated the fatty liver formation when compared with controls, as well as the inflammatory cytokines production [29]. Similar effect of SIRT1 on steatosis and inflammation aggravation is also reported in SIRT1 whole-body heterozygous mice under mediate- or high-fat diet feeding condition [27]. Conversely, overexpression of SIRT1 could protect Sirt1 transgenic mice from high-fat diet induced hepatic steatosis, hepatic glucose intolerance, and hepatic inflammation [30]. Taken together, all these phenotypic evidences from either SIRT1 deficient or transgenic mice, as summarized in table 1, demonstrate that SIRT1 play important roles in negatively regulating fatty liver diseases initiation and progression. In the following parts, we will specifically review the underlying mechanism in detail.
A

\begin{tabular}{|l|c|l|}
\hline \multicolumn{1}{|c|}{ Age } & SIRT1 flox5-6 & SIRT1LKO \\
\hline 2 Months & $0 / 7(0 \%)$ & $2 / 7(28.6 \%)$ \\
\hline 6 Months & $1 / 9(11.1 \%)$ & $5 / 9(55.9 \%)$ \\
\hline 8 Months & $1 / 8(12.5 \%)$ & $4 / 8(50 \%)$ \\
\hline$\geqslant 12$ Months & $2 / 12(16.6 \%)$ & $7 / 9(77.8 \%)$ \\
\hline
\end{tabular}

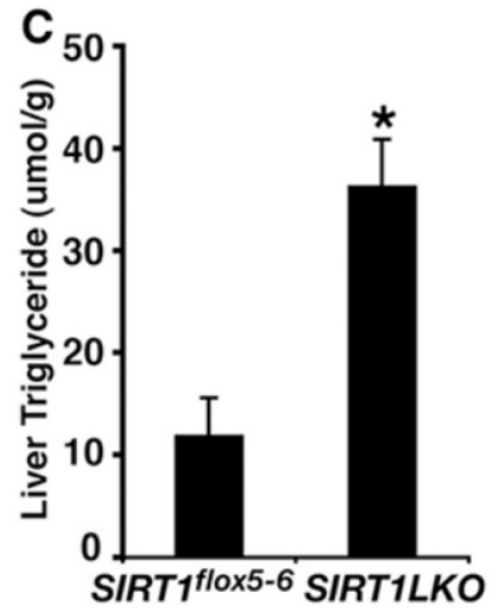

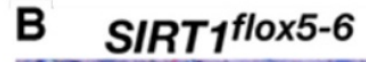

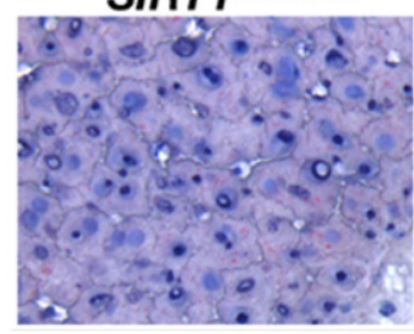

SIRT1LKO

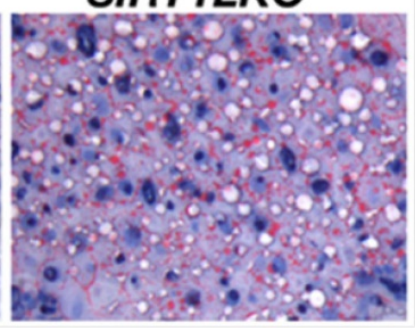

E

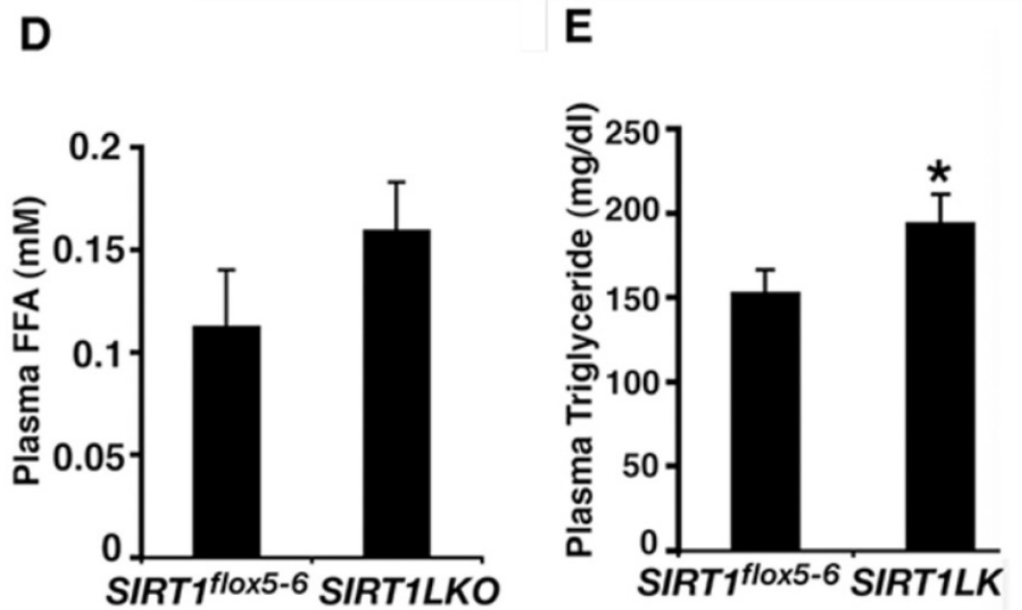

Figure 3. SIRT1 liver-specific knockout causes liver steatosis. (A) Summary of fatty liver cases at different age among control (Sirt lflox5-6) and liver-specific SIRT1 knockout (Sirt l LKO) male mice. (B) Oil Red O staining of 14 months old male liver with higher magnification. (C-E) Liver TG content (C), plasma FFA amount (D) and plasma TG content (E) of 9 months old male mice $(n=11) .{ }^{*} p<0.05$. (Adapted from Wang et al. 2010 [68]) 
Table 1. Lessons from genetic mouse models on SIRT1 related to fatty liver diseases

\begin{tabular}{|c|c|c|c|c|c|c|}
\hline & Modification of SIRT1 & Diet & Main metabolic phenotypes related to fatty liver diseases & $\begin{array}{l}\text { Targets for } \\
\text { SIRT1 }\end{array}$ & $\begin{array}{l}\text { Involved } \\
\text { mechanisms }\end{array}$ & Ref. \\
\hline 1 & $\begin{array}{l}\text { SIRT1 heterozygous mice } \\
\text { (exon } 4 \text { ) }\end{array}$ & $\begin{array}{l}\text { Mediate-fat diet; } \\
\text { High-fat diet }\end{array}$ & $\begin{array}{l}\text { SIRT1 deficiency mice show more hepatic lipid accumulation and } \\
\text { inflammatory cytokines production than control mice }\end{array}$ & SREBP-1c & $\begin{array}{l}\text { 个Lipogenesis; } \\
\text { 个Inflammation }\end{array}$ & [27] \\
\hline 2 & $\begin{array}{l}\text { Liver-specific SIRT1 } \\
\text { knockout mice (exon 5-6) }\end{array}$ & Standard diet & $\begin{array}{l}\text { SIRT1 deficiency mice show more hepatic lipid accumulation than } \\
\text { control mice }\end{array}$ & ChREBP & 个Lipogenesis & {$[68]$} \\
\hline 3 & $\begin{array}{l}\text { Liver-specific SIRT1 } \\
\text { knockout mice (exon 5-6) }\end{array}$ & Standard diet & $\begin{array}{l}\text { SIRT1 deficiency mice show more ROS production, hyperglycemia and } \\
\text { insulin resistance than control mice }\end{array}$ & Rictor & 个Oxidative stress & [69] \\
\hline 4 & $\begin{array}{l}\text { Liver-specific SIRT1 } \\
\text { knockout mice (exon } 4)\end{array}$ & High-fat diet & $\begin{array}{l}\text { SIRT1 deficiency mice show more hepatic lipid accumulation and } \\
\text { inflammatory cytokines production than control mice }\end{array}$ & $\begin{array}{l}\text { PPARa/PGC-1 } \\
\text { a }\end{array}$ & $\downarrow_{F A} \beta$-oxidation & {$[28]$} \\
\hline 5 & $\begin{array}{l}\text { Liver-specific SIRT1 } \\
\text { knockout mice (exon } 4)\end{array}$ & Alcoholic diet & $\begin{array}{l}\text { SIRT1 deficiency mice show more liver injury and liver fibrosis than } \\
\text { control mice }\end{array}$ & PDGFR- $\alpha$ & 个Inflammation & [59] \\
\hline 6 & $\begin{array}{l}\text { Liver-specific SIRT1 } \\
\text { knockout mice (exon 4) }\end{array}$ & Alcoholic diet & $\begin{array}{l}\text { SIRT1 deficiency mice show more hepatic lipid accumulation and } \\
\text { inflammatory cytokines production than control mice }\end{array}$ & Lipin-1 & 个Inflammation & [29] \\
\hline 7 & $\begin{array}{l}\text { Liver-specific SIRT1 } \\
\text { knockout mice (exon } 4 \text { ) }\end{array}$ & Prolonged fasting & $\begin{array}{l}\text { SIRT1 deficiency mice show more hepatic lipid accumulation than } \\
\text { control mice }\end{array}$ & PPARa/FGF21 & $\downarrow$ FA $\beta$-oxidation & [134] \\
\hline 8 & $\begin{array}{l}\text { Liver-specific SIRT1 } \\
\text { knockout mice (exon 4) }\end{array}$ & High-fat diet & $\begin{array}{l}\text { SIRT1 deficiency mice show less hepatic lipid accumulation than control } \\
\text { mice (inconsistent with other studies) }\end{array}$ & SREBP-1c & $\downarrow_{\text {Lipogenesis }}$ & [67] \\
\hline 9 & $\begin{array}{l}\text { Liver-specific SIRT1 } \\
\text { knockdown mice }\end{array}$ & Standard diet & $\begin{array}{l}\text { SIRT1 deficiency mice show more hepatic lipid accumulation and } \\
\text { hyperglycemia than control mice }\end{array}$ & $\begin{array}{l}\text { PGC-1a; } \\
\text { SREBP-1c }\end{array}$ & $\boldsymbol{\uparrow}$ Lipogenesis & [92] \\
\hline 10 & $\begin{array}{l}\text { Fat-specific SIRT1 } \\
\text { knockout mice }\end{array}$ & High-fat diet & $\begin{array}{l}\text { SIRT1 deficiency mice show more adipose macrophage infiltration and } \\
\text { inflammatory cytokines production than control mice }\end{array}$ & NF-kB & 个Inflammation & [117] \\
\hline 11 & $\begin{array}{l}\text { Fat-specific SIRT1 } \\
\text { knockout mice (exon } 4)\end{array}$ & High-fat diet & $\begin{array}{l}\text { SIRT1 deficiency mice show increased or reduced inflammation in } \\
\text { adipose tissue on short-term or chronic high-fat diet respectively } \\
\text { compared to control mice }\end{array}$ & PPARY & $\begin{array}{l}\text { Inflammation or } \\
\boldsymbol{\Downarrow} \text { Inflammation }\end{array}$ & [156] \\
\hline 12 & $\begin{array}{l}\text { Myeloid-specific SIRT1 } \\
\text { knockout mice (exon 4) }\end{array}$ & High-fat diet & $\begin{array}{l}\text { SIRT1 deficiency mice show more inflammatory cytokines production } \\
\text { than control mice }\end{array}$ & NF-kB & 个Inflammation & [115] \\
\hline 13 & $\begin{array}{l}\text { Myeloid-specific SIRT1 } \\
\text { knockout mice (exon 4) }\end{array}$ & High-fat diet & $\begin{array}{l}\text { SIRT1 deficiency mice show more hepatic lipid accumulation, peroxides } \\
\text { production and macrophage infiltration than control mice }\end{array}$ & NF-kB & 个Inflammation & [114] \\
\hline 14 & $\begin{array}{l}\text { Myeloid-specific SIRT1 } \\
\text { knockout mice (exon 4) }\end{array}$ & High-fat diet & $\begin{array}{l}\text { SIRT1 deficiency mice show more hepatic macrophage infiltration and } \\
\text { inflammatory cytokines production than control mice than control mice }\end{array}$ & NF-kB & 个Inflammation & [157] \\
\hline 15 & $\begin{array}{l}\text { Myeloid-specific SIRT1 } \\
\text { knockout mice (exon } 4)\end{array}$ & High-fat diet & $\begin{array}{l}\text { SIRT1 deficiency mice show more hepatic lipid accumulation and } \\
\text { inflammatory cytokines production than control mice }\end{array}$ & $\begin{array}{l}\text { NF-kB; } \\
\text { SREBP-1c }\end{array}$ & $\begin{array}{l}\text { 个Inflammation; } \\
\text { 个Lipogenesis }\end{array}$ & [158] \\
\hline 16 & $\begin{array}{l}\text { Fat-specific SIRT1 } \\
\text { overexpressing mice }\end{array}$ & Standard diet & $\begin{array}{l}\text { SIRT1 overexpressing mice show increased adipose tissue lipolysis } \\
\text { compared to control mice }\end{array}$ & $\mathrm{ACC} 1$ & 个Lipolysis & [147] \\
\hline 17 & SIRT1 overexpressing mice & Alcoholic diet & $\begin{array}{l}\text { SIRT1 overexpressing mice show less liver injury and liver fibrosis than } \\
\text { control mice }\end{array}$ & PDGFR- $a$ & $\downarrow$ Inflammation & [59] \\
\hline 18 & SIRT1 overexpressing mice & High-fat diet & $\begin{array}{l}\text { SIRT1 overexpressing mice show less hepatic lipid accumulation and } \\
\text { inflammatory cytokines production than control mice }\end{array}$ & $\begin{array}{l}\text { SREBP-1c; } \\
\text { MnSOD; NF-kB }\end{array}$ & $\begin{array}{l}\text { \Oxidative stress } \\
\text { \Inflammation }\end{array}$ & {$[30]$} \\
\hline 19 & SIRT1 overexpressing mice & High-fat diet & $\begin{array}{l}\text { SIRT1 overexpressing mice show less adipose macrophage infiltration } \\
\text { than control mice }\end{array}$ & $\mathrm{NF}-\mathrm{kB}$ & \Inflammation & [117] \\
\hline
\end{tabular}

\section{Role of SIRT1 in hepatic lipid metabolism}

Lipid metabolism disorder is one of the most important predisposing factors in fatty liver diseases pathogenesis, which is characterized by abnormal excessive lipid accumulation in the liver. Lipogenesis (lipid synthesis) and fatty acid $\beta$-oxidation (lipid utilization) are two major regulations that are responsible for this impaired hepatic lipid balance during fatty liver development. Recent studies demonstrated that SIRT1 plays a central beneficial role in controlling hepatic lipid metabolism as well as protects against high-fat diet or alcohol consumption induced hepatic steatosis primarily through regulating lipogenesis and fatty acid $\beta$-oxidation (Figure 1). We will describe them below.

\section{Lipogenesis}

Hepatic de novo lipogenesis is an important lipid source for TG deposition in the liver [3, 35]. Generally, there are two major transcriptional factors tightly controlling this TG synthesis process, which are insulin signaling responded SREBP-1c and glucose status associated ChREBP $[3,71]$. Evidence has shown that both SREBP-1c and ChREBP are positive regulators for many lipogenic genes, including Acetyl-CoA carboxylase 1 (ACC1), fatty acid synthase (FAS) and so on [68]. SREBPs are DNA binding transcription factors that are critically involved in lipid synthesis regulation by binding to the promoter regions of its target lipogenic genes [72]. There are three isoforms of SREBPs: SREBP-1a, SREBP-1c, and SREBP-2 [73]. Among them, SREBP-1c is primarily expressed in the liver and is responsible for hepatic TG synthesis regulation [72]. After activated, SREBP-1c binds to and activates its downstream lipogenic genes, such as FAS, ACC1, stearoyl-CoA desaturase-1 (SCD1) to stimulate hepatic lipogenesis [74].

Recent studies revealed that SIRT1 down-regulates the transcriptional activity of SREBP-1c by deacetylating at Lys-289 and Lys-309 in the DNA binding domain of SREBP-1c, while acetylation at the same site by p300/CBP acetylase increases SREBP-1c transactivation [75-77]. Deacetylation of SREBP-1c by SIRT1 promotes the ubiquitination and proteasomal degradation [72], and 
decreases its stability and occupancy at the lipogenic genes [75]. Consistently, overexpression of SIRT1 in mice using adenovirus decreases acetylated SREBP-1c levels with suppressed SREBP-1c and lipogenic genes expression [75], whereas down-regulating SIRT1 by adenoviral siRNA or its inhibitors, nicotinamide and sirtinol, increases acetylation of SREBP-1c and its related lipogenic gene expression [75, 76]. Remarkably, SREBP-1c acetylation levels are significantly elevated in the fatty liver of high-fat diet induced obese mice, and adenovirus mediated overexpression of SIRT1 could attenuate this hepatic steatosis and related SREBP-1c mediated lipogenesis signaling [75]. Similarly, treatments with chemical activators of SIRT1, resveratrol and SRT1720, or $\mathrm{NAD}^{+}$precursor nicotinamide riboside also decrease SREBP-1c and related hepatic lipogenic gene and protein profiles, such as FAS, SCD1, and ACC1, thereby protecting liver against high-fat or high-fat plus high-sucrose diet induced hepatic steatosis [75, 78-80]. Consistent with the findings from NAFLD, SIRT1 also shows similar beneficial effect on alcohol-induced fatty liver diseases. Activation of SIRT1 by resveratrol abolishes ethanol-induced hyperacetylation of SREBP-1c and its increased transcriptional activity, and suppresses SREBP-1c mediated lipogenesis to alleviate alcoholic hepatic steatosis [81, 82]. Whereas hepatic SIRT1 deficiency in mice aggravates alcohol induced acetylated active nuclear form of SREBP-1 protein expression up-regulation and its regulated lipogenic enzymes mRNA expression, including FAS, SCD1 and ACC1, compared with alcohol treated control mice [29].

Besides SREBP-1c, ChREBP is another major transcription factor that involves in lipogenesis, which acts synergistically with SREBP-1c to fully stimulate TG synthesis [83]. Activation of ChREBP can be induced by high circulating glucose and fatty acids level through multiple post-transcriptional modifications, mostly phosphorylation and acetylation [84], and SIRT1 deficiency in mice could significantly elevate blood glucose and fatty acids level $[68,69]$. It is reported that increased ChREBP acetylation is associated with both high-fat diet induced, and alcohol-induced hepatic steatosis, as well as increased ChREBP transcription activity and its target lipogenic genes expression [83, 85, 86], which is consistent with the suppression of SIRT1 expression and deacetylating activity in NAFLD and AFLD [81, 85-87]. Moreover, further direct evidence is provided from liver-specific SIRT1 knockout mice, which exhibits increased ChREBP expression associated with elevated acetylation of histone H3K9 and histone H4K16 on upstream of ChREBP promoter, and up-regulated ChREBP targeted lipogenic gene expression, FAS, ACC1 and elongase of long chain fatty acids family 6 (ELOVL6), consequently leads to hepatic steatosis under a normal feeding condition [68]. These data uncover an essential role of SIRT1 in regulating ChREBP related lipogenesis possibly through histone deacetylation on upstream of ChREBP promoter, thereby controlling lipid homeostasis in the liver.

\section{Fatty acid $\beta$-oxidation}

Fatty acid $\beta$-oxidation is a major mean of TG utilization in liver, and PPARa/PGC-1a signaling pathway plays an essential role in regulating this process. PPARa is a ligand-activated transcription factor, and its primary endogenous ligands are fatty acids [88, 89]. Upon fatty acid binding, PPARa induces the expression of genes related to fatty acid catabolism in mitochondrial matrix [89]. PGC-1a is a transcriptional co-activator that interacts with PPARa to promote transcription of PPAR- $\alpha$ and, consequently, induces expression of fatty acid catabolic genes [28]. SIRT1 increases PPARa transcriptional activity primarily through its ability to deacetylate the co-activator PGC-1 $\alpha$ to promote fatty acid $\beta$-oxidation in the liver $[28,90,91]$. It has been showed that liver-specific knockout SIRT1 or adenoviral-mediated liver-specific acute down-regulation of SIRT1 in mice causes PPARa transcriptional signal failure, which is associated with increased acetylation of PGC-1 $\alpha$ and results in reduction of fatty acid $\beta$-oxidation as well as increased susceptibility of mice to high fat diet to induce hepatic steatosis [28]. Whereas overexpression of SIRT1 using adenovirus reduces PGC-1a acetylation level and ligand-dependent PPARa transcriptional signaling as well as the expression of PPARa/PGC-1a targeting genes, which leads to increased fatty acid $\beta$-oxidation and alleviation of fatty liver [28, 92]. Similar results were also obtained from high-fat or high-fat plus high-sucrose diet induced fatty liver mice treated with chemical SIRT1 agonists, SRT1720 and resveratrol, or $\mathrm{NAD}^{+}$precursor nicotinamide riboside [80, 93, 94]. Similarly to the action in response to high-fat diet, hepatic fatty acid $\beta$-oxidation is also impaired by alcohol intake through down-regulating the activity of SIRT1 and PGC-1a, as well as their targeting gene and protein expression $[95,96]$. In ethanol fed liver-specific knockout mice, SIRT1 ablation further suppresses the mRNA expression levels of several PPARa/PGC-1a signaling enzymes involved in fatty acid $\beta$-oxidation [29]. Conversely, activating SIRT1 by resveratrol treatment reverses this effect associated with activation of PGC-1a, consequently alleviates alcoholic fatty liver in mice [82]. 
Collectively, these data indicate that SIRT1 acts as an essential regulator in hepatic lipid metabolism as summarized in figure 1, mainly through the control of SREBP-1c/ChREBP-dependent lipogenesis and PPARa/PGC-1a-dependent fatty acid $\beta$-oxidation, thereby inhibiting lipid synthesis and increasing lipid utilization respectively to benefit the fatty liver induced by high-fat diet and/or alcohol consumption. In addition to the direct regulation on lipid metabolism through SIRT1, study from our group on interaction between SIRT1 and SIRT6 reveals that SIRT1 also positively regulates SIRT6 gene expression by forming a complex together with FOXO3a and the nuclear respiratory factor 1 (NRF1) on the promoter of SIRT6, and SIRT6, in turn, deacetylates histone H3K9 of promoter of many genes involved in lipogenesis, fatty acid $\beta$-oxidation and glycolysis [23]. Our liver-specific SIRT6 knockout mice spontaneously develop fatty liver starting from 5-6 months age at a frequency of $43 \%(3 / 7)$, and reaches $90 \%(9 / 10)$ at 7.5-13 months of age [23], which uncovers an important role of SIRT1 in the regulation of lipid metabolism through SIRT6.

\section{Role of SIRT1 in hepatic oxidative stress}

Hepatic oxidative stress is a well-established major contributor that is responsible for the pathogenesis of liver damage, specifically contributing to lipid peroxidation, mitochondrial dysfunction, and apoptosis in the liver [36]. The magnitude of oxidative stress is commonly based on imbalance levels between ROS production and antioxidant capacity [97]. Mitochondria are the most important cellular source of ROS [98], and mitochondria-derived ROS is generated through either mitochondrial respiration or the action of several oxidases, like NADPH oxidase [97]. On the other hand, the excessive ROS-induced oxidative stress can be detoxified by several antioxidant enzymes, including superoxide dismutase (SOD), catalase (CAT), and glutathione peroxidase (GPX) [99]. Fork head box proteins (FOXO1, FOXO3, FOXO4) and PGC-1a are key transcription factors involved in redox regulation via activating the transcription of antioxidant enzyme genes to increase ROS-detoxifying capacity [100, 101]. It has been reported that SIRT1 has a regulatory effect on oxidative stress through deacetylating of FOXOs and PGC-1a to increase their transcriptional activity on antioxidant enzyme genes [90, 102-105]. In NAFLD induced by high-fat diet, activation of SIRT1 with either $\mathrm{NAD}^{+}$precursor nicotinamide riboside or SRT1720 could deacetylate and activate FOXO1 and PGC-1a transcriptional activity, then lead to higher expression of target antioxidant genes, subsequently protect against hepatic oxidative stress in fatty liver [93, 106]. Consistently, in another study of high-carbohydrate induced fatty liver diseases, resveratrol treatment significantly increases antioxidant enzymes including SOD, CAT and GPX, and reduces pro-oxidant - nitric oxide synthase and lipid peroxidation product - malondialdehyde (MDA), thus exhibits anti-oxidative stress effect in fatty liver [107]. Similar results can also be found in alcoholic fatty liver diseases where activation of SIRT1 deacetylase activity by resveratrol enhances PGC-1a transcriptional activity and attenuates oxidative stress as judged by decreasing MDA levels [82]. Furthermore, genetic models in which SIRT1 expression level is modulated also provide more direct supports for the regulatory role of SIRT1 on oxidative stress. In transgenic mice, SIRT1-overexpression increases the expression of antioxidant protein manganese-dependent superoxide dismutase (MnSOD) and NRF1, a crucial regulator protecting from ROS, which protect the mice from high-fat induced hepatic oxidative stress and fatty liver [30]. Conversely, hepatic SIRT1 deletion significantly increases ROS levels in the liver as well as in multiple other tissues, consequently leading to severe hepatic oxidative stress and eventually fatty liver diseases [29, 68, 69].

In summary, SIRT1 supports a beneficial effect on hepatic oxidative stress as well as associated fatty liver diseases, and this protective action is possibly through stimulation of FOXOs and PGC-1a (Figure 2). However, proofs for critical regulation of SIRT1 on oxidative stress, especially how SIRT1 directly regulates FOXOs and PGC-1a and their downstream antioxidant genes in fatty liver diseases still need further investigation.

\section{Role of SIRT1 in hepatic inflammation}

Growing evidences link inflammation to the initiation of liver injury and the progression of hepatic steatosis to steatohepatitis, which are characterized by presence of macrophage infiltration and high levels of pro-inflammatory cytokines [4, 46-48]. The transcription factor nuclear factor- $\mathrm{kB}(\mathrm{NF}-\mathrm{kB})$ and its signaling pathway play central roles in this inflammation process [108]. NF-KB forms as a heterodimeric protein complex containing a DNA-binding component and a transactivation domain [109]. The most ubiquitous NF-kB dimer is RelA/p65 heterodimer that held in the cytoplasm complexed with its inhibitory protein IкB [110]. Once inflammatory response is triggered, IKB becomes phosphorylated by the IкB kinase and targeted for its ubiquitination and degradation [101]. Following IкB degradation, NF- $\mathrm{kB}$ is able to be released from ІкB 
and translocate into nucleus to mediate p300/CBP recruitment, while acetylating RelA/p65 by p300/CBP activates NF- $\mathrm{KB}$ transcription, consequently enhances downstream genes involved in pro-inflammation $[109,111]$. It has been showed that SIRT1 interacts with RelA/p65, a sub-unit of NF-kB and inhibits its transcriptional activity by deacetylating RelA/p65 at lysine $310[112,113]$.

More and more evidences indicate that SIRT1 incorporates in the pathogenesis of inflammation associated fatty liver diseases. It is reported that liver-specific knockout SIRT1 or whole-body SIRT1 heterozygous knockout could significantly increase macrophage accumulation and infiltration accompanied with higher levels of macrophage markers expression in the liver, such as macrophage inflammatory proteins 1 a (MIP1a), F4/80 and $\mathrm{CD} 11 \beta$, in response to high-fat diet challenge $[27,28]$. Meanwhile, several pro-inflammatory cytokines (i.e. IL-1, IL-6 and TNF- $\alpha$ ) are also induced in these SIRT1 deficient mouse models [27, 28]. Consequently, the deletion of SIRT1 exacerbates the development of hepatic inflammation and fatty liver diseases when challenged with high-fat diet or even mediate-fat diet $[27,28]$. Consistent with these observations, myeloid cell-specific disruption of SIRT1 in mice reveals that SIRT1 deficiency in macrophages induces NF-kB hyperacetylation and increases NF-kB transcriptional activation in the liver, resulting in hepatic inflammation [114] and hepatic steatosis upon high-fat diet [115], whereas overexpression of SIRT1 in transgenic mice shows beneficial effects on fatty liver induced by high-fat diet and lower activation of pro-inflammatory cytokines, such as IL-6 and TNF-a, via down-regulation of NF-kB activity [30]. These results are consistent to those with activation of SIRT1 by resveratrol or nicotinamide riboside treatment under high-fat or high-fat plus high-sucrose diet conditions [78, 80, 87, 107, 116]. Similarly, SIRT1 agonist, resveratrol, also exhibits anti-inflammation effects in ethanol metabolite-treated macrophages via down-regulating NF- $\mathrm{kB}$ transcriptional activity and TNF- $\alpha$ production [113]. In addition to local inflammation in the liver, adipose tissue-derived inflammation and its pro-inflammatory cytokines release into circulation are also important causes contributing to pathogenesis of fatty liver diseases, especially hepatic inflammation. Several studies demonstrate that SIRT1 also play a crucial role in the regulation of adipose tissue inflammation in response to high-fat induced fatty liver diseases [27, 114, 115]. From the analyses of all these SIRT1 mutant mice, it is clear that the SIRT1 deficiency induces macrophage infiltration and inflammatory cytokines release through NF-kB transcriptional activity up-regulation in adipose tissue, subsequently results in increased adipose tissue inflammation as well as hepatic inflammation [27, 114, 115, 117], whereas genetic overexpression of SIRT1 prevents adipose tissue macrophage infiltration and inflammation induced by high-fat feeding [117].

These data indicate that SIRT1 is an essential negative inflammatory regulator in high-fat diet or alcohol induced fatty liver diseases, mainly through deacetylating NF- $\mathrm{kB}$ and down-modulating NF-KB transcriptional activity, thereby reducing macrophage infiltration and pro-inflammatory cytokines production in the liver as well as in the adipose tissue (Figure 2).

\section{SIRT1 as a therapeutic target for fatty liver diseases}

Increasing attentions have been paid to the therapy of fatty liver diseases, as its prevalence is increasing dramatically in recent years. Meanwhile, it is getting clear that fatty liver diseases are also commonly associated with many other metabolic complications, such as insulin resistance, hyperlipidemia, consequently increase the high risk of obesity and type 2 diabetes mellitus [3]. However, there are no specific and effective medicinal therapies for alcoholic or non-alcoholic fatty liver diseases, except restricting patients with less-alcohol consumption, low-fat/low-calorie diet intake and more physical exercise. Thus, the demand of identifying new therapeutic targets for fatty liver diseases and developing corresponding agents is necessary and urgent.

Because SIRT1 plays essential and beneficial roles in various metabolic pathways involved in fatty liver and other metabolic disorders [6, 22, 27-32, 118], many studies have tested if pharmacological activation of SIRT1 could serve as an effective therapeutic approach for preventing the development of fatty liver diseases at all stages, including the onset, progression and complication, as summarized in table 2. Shortly after the natural polyphenolic compound resveratrol was identified as direct SIRT1 activator for the first time [119], extensive in vivo studies in mammal models have been investigated on its protective functions against fatty liver diseases. From these studies, resveratrol exhibits a wide spectrum of beneficial effects involved in controlling lipid metabolism, oxidative stress and inflammation to ameliorate fatty liver diseases $[33,78,79,82,87,107$, $116,120,121]$. In addition to resveratrol, a few other natural polyphenols also present similar beneficial effects through SIRT1 activation [122-128]. However, natural polyphenols are not specific and potent to activate SIRT1 in mammals [129-131], several new 
SIRT1 agonists with higher specificity and potency are developed, like SRT1720 discovered by Sirtris Pharmaceuticals [132], and show great protective effect against NAFLD [93, 133, 134]. Of note, some existing approved drugs also elicit promising therapeutic effects on fatty liver diseases through activation SIRT1 and a number of other signaling molecules, for example, Olaparib, a Poly (ADP-ribose) polymerase (PARP) inhibitor. The protective effects of Olaparib and other PAPR inhibitors against NAFLD and AFLD have been intensively reported during recent several months [135-138]. Through restoring $\mathrm{NAD}^{+}$levels and increasing the activity of SIRT1, but not the activity of SIRT2 and SIRT3 [139], PARP inhibition reduces steatosis formation, oxidative stress and inflammation in the liver and prevents steatohepatitis and fibrosis progression in a SIRT1-dependet manner [135-138]. Given that PARP inhibitors are already FDA-approved drugs for other diseases, such as cancer, these agents possess the promising potential to be repurposed for use in the fatty liver diseases.

Table 2. Summary of pharmacological studies about identified SIRTI activators and other potential chemical agents in animal models of fatty liver diseases

\begin{tabular}{|c|c|c|c|c|}
\hline Chemical agents & Models & Possible targets & Involved mechanisms & Ref. \\
\hline Resveratrol & NAFLD & SIRT1-PPAR-ү/PPAR- $\alpha$ & $\boldsymbol{\downarrow}$ Lipogenesis; $\uparrow$ FA $\beta$-oxidation & {$[33]$} \\
\hline Resveratrol & NAFLD & SIRT1-AMPK/SREBP-1c & $\downarrow$ Lipogenesis & [120] \\
\hline Resveratrol & NAFLD & SIRT1-AMPK/PGC-1a/SREBP-1c & $\downarrow$ Lipogenesis; $\uparrow$ FA $\beta$-oxidation & [79] \\
\hline Resveratrol & NAFLD & SIRT1-SREBP-1c/NF-кB & $\downarrow_{\text {Lipogenesis; } \downarrow \text { Inflammation }}$ & [78] \\
\hline Resveratrol & NAFLD & SIRT1-AMPK/ NF-kB & $\downarrow$ Inflammation & [116] \\
\hline Resveratrol & NAFLD & - & $\downarrow$ Oxidative stress & [107] \\
\hline Resveratrol & NAFLD & - & $\downarrow$ Inflammation & [87] \\
\hline Resveratrol & NAFLD & SIRT1- PPARa-FGF21 & 个FA $\beta$-oxidation & [134] \\
\hline Resveratrol & NAFLD & SIRT1-LXRa & $\downarrow$ Lipogenesis & [121] \\
\hline Resveratrol & AFLD & SIRT1-AMPK/PGC-1a/SREBP-1c & $\boldsymbol{\downarrow}$ Lipogenesis; $\uparrow$ FA $\beta$-oxidation & [82] \\
\hline Resveratrol & AFLD & SIRT1-AMPK & $\downarrow$ Lipogenesis & [159] \\
\hline SRT1720 & NAFLD & SIRT1-PGC-1a/SREBP-1c & $\downarrow$ Lipogenesis; $\downarrow$ Inflammation & [133] \\
\hline SRT1720 & NAFLD & SIRT1-AMPK/PGC-1a/PPARa/FOXO1 & $\uparrow F A \beta$-oxidation; $\downarrow$ Oxidative stress & [93] \\
\hline SRT1720 & NAFLD & SIRT1- PPARa-FGF21 & 个FA $\beta$-oxidation & [134] \\
\hline a-Lipoic acid & NAFLD & SIRT1-LKB1/AMPK/SREBP-1c/FOXO1/Nrf2 & $\downarrow$ Lipogenesis; $\downarrow$ Oxidative Stress & [160] \\
\hline a-Lipoic acid & NAFLD & SIRT1-AMPK/LKB1 & $\downarrow$ Lipogenesis; $\uparrow F A \beta$-oxidation & [161] \\
\hline$\alpha$-Mangostin & NAFLD & SIRT1-AMPK/ PPAR- $\gamma$ & - & [122] \\
\hline Apo-10'-Lycopenoic Acid & NAFLD & SIRT1-FOXO1 & - & [162] \\
\hline Cardiotrophin-1 & NAFLD & SIRT1-AMPK/LKB1/SREBP-1c/PGC-1a & $\boldsymbol{\downarrow}$ Lipogenesis; $\uparrow$ FA $\beta$-oxidation & [163] \\
\hline Carnosic acid & NAFLD & SIRT1-p66shc & $\downarrow$ Oxidative stress & [123] \\
\hline Carvacrol & NAFLD & SIRT1-AMPK/SREBP-1c & $\boldsymbol{\Downarrow}$ Lipogenesis; $\Downarrow_{\text {Inflammation }}$ & [124] \\
\hline Cobalt protoporphyrin & NAFLD & HO-1-SIRT1-SREBP-1c & $\downarrow_{\text {Lipogenesis; }} \downarrow$ Oxidative stress; $\downarrow$ Inflammation & [164] \\
\hline Cobalt protoporphyrin & NAFLD & HO-1- SIRT1-PPARa/AMPK & $\downarrow$ Lipogenesis; $\downarrow$ Oxidative stress; $\downarrow$ Inflammation & [165] \\
\hline Epigallocatechin-3-gallate & NAFLD & SIRT1-AMPK/LKB-SREBP-1c/ChREBP & $\boldsymbol{\downarrow}$ Lipogenesis; & [125] \\
\hline Exendin- 4 & NAFLD & SIRT1-AMPK/LKB1/SREBP-1c/FOXO1 & $\downarrow$ Lipogenesis; $\uparrow F A$-oxidation & [166] \\
\hline Exendin-4 & NAFLD & SIRT1-FGF21 & 个FA $\beta$-oxidation & [167] \\
\hline Indole-3-carbinol & NAFLD & SIRT1-AMPK/SREBP-1c & $\downarrow$ Lipogenesis; $\downarrow$ Inflammation & [168] \\
\hline Leucine & NAFLD & SIRT1-PGC-1a/FOXO1 & 个FA $\beta$-oxidation & [34] \\
\hline Lipoic acid & NAFLD & SIRT1-PGC-1a/FOXO3a & $\downarrow$ Oxidative stress & [169] \\
\hline Methylene blue & NAFLD & SIRT1-PGC-1a/PPARa/AMPK/SREBP-1c & $\downarrow$ \Lipogenesis & [170] \\
\hline N1-methylnicotinamide & NAFLD & SIRT1-FOXO1 & $\boldsymbol{\downarrow}$ Lipogenesis; $\boldsymbol{V}_{\text {Inflammation }}$ & [171] \\
\hline Nicotinamide riboside & NAFLD & SIRT1-FOXO1 & $\downarrow$ Oxidative stress & [106] \\
\hline Nicotinamide riboside & NAFLD & SIRT1-NLRP3 & $\downarrow$ Inflammation & [172] \\
\hline Nicotinamide riboside & NAFLD & SIRT1-PPAR- $/$ / SREBP-1c/ PPARa/ PGC-1a/Nrf1 & $\boldsymbol{\downarrow}$ Lipogenesis; $\uparrow F A$-oxidation; $\downarrow$ Inflammation & {$[80]$} \\
\hline Olaparib (PARP inhibitor) & NAFLD & SIRT1-SREBP-1c/ PPARa & $\downarrow$ Lipogenesis; $\downarrow$ Oxidative stress; $\downarrow$ Inflammation & [135] \\
\hline Olaparib (PARP inhibitor) & NAFLD & - & $\uparrow F A$-oxidation; $\downarrow$ Oxidative stress; $\downarrow$ Inflammation & [136] \\
\hline Pifithrin- $\alpha \rho$-nitro & NAFLD & SIRT1-PGC-1a/PPARa; SIRT1-LKB1/AMPK & 个FA $\beta$-oxidation & [173] \\
\hline Salvianolic acid B & NAFLD & SIRT1-HMGB1-NF-кB/TLR4 & $\downarrow$ Inflammation & [126] \\
\hline (S)YS-51 & NAFLD & SIRT1-AMPK/LKB1/SREBP-1c & $\downarrow$ Lipogenesis; $\downarrow$ Inflammation & [174] \\
\hline Quercetin & NAFLD & SIRT1-NF-кB & $\downarrow$ Inflammation & [128] \\
\hline PJ-34 (PARP inhibitor) & NAFLD & SIRT1- PPARa & 个FA $\beta$-oxidation & [137] \\
\hline Troxerutin & NAFLD & SIRT1-AMPK & $\boldsymbol{\downarrow}$ Lipogenesis; $\uparrow$ FA $\beta$-oxidation; $\downarrow$ Oxidative Stress & [175] \\
\hline 14-Deoxyandrographolide & AFLD & SIRT1-AMPK/SREBP-1c & $\downarrow$ Lipogenesis & [176] \\
\hline $\begin{array}{l}\text { 5-Aminoisoquinoline (PARP } \\
\text { inhibitor) }\end{array}$ & AFLD & SIRT1-SREBP-1c/ PGC-1a/ FOXO1 & $\boldsymbol{\downarrow}$ Lipogenesis; $\downarrow$ Oxidative stress; $\downarrow$ Inflammation & [135] \\
\hline Demethyleneberberine & AFLD & SIRT1-AMPK-PGC-1a & 个FA $\beta$-oxidation & [177] \\
\hline Salvianolic acid B & AFLD & SIRT1-ChREBP & $\downarrow_{\text {Lipogenesis; }} \downarrow_{\text {Inflammation }}$ & [127] \\
\hline Olaparib (PARP inhibitor) & AFLD & SIRT1- PGC-1a/ FOXO1 & $\boldsymbol{\downarrow}$ Lipogenesis; $\downarrow$ Oxidative stress; $\downarrow$ Inflammation & [135] \\
\hline PJ-34 (PARP inhibitor) & AFLD & SIRT1- PPARa/ NF-KB & $\boldsymbol{\downarrow}$ Lipogenesis; $\boldsymbol{\uparrow} F A$-oxidation; $\downarrow$ Inflammation & [138] \\
\hline PJ-34 (PARP inhibitor) & AFLD & SIRT1-SREBP-1c/ PGC-1a/ FOXO1 & $\downarrow$ Lipogenesis; $\downarrow$ Oxidative stress; $\downarrow$ Inflammation & [135] \\
\hline Rosiglitazone & AFLD & SIRT1-AMPK/PGC-1a/FOXO1 & $\downarrow$ \Lipogenesis; $\uparrow F A$-oxidation & [178] \\
\hline
\end{tabular}


With the confidence obtained from animal studies, multiple human clinical trials have being conducted to explore the pharmacological potential of resveratrol to treat fatty liver and various human metabolic diseases (Table 3), and at least two of them have been advanced to phase IV clinical trial for treating gestational diabetes (NCT01997762) and polycystic ovary syndrome (PCOS) with insulin resistance (NCT02766803). Of note, five of these human trials on resveratrol are specifically targeted for fatty liver diseases treatment (NCT02216552, NCT02030977, NCT01446276, NCT01635114 and NCT01464801), and two of them are currently at phase III clinical trial stage. But to our great surprise, the clinical trial case reports on the effect of resveratrol against fatty liver diseases from four independent groups are inconsistent, two groups claimed that 3-month resveratrol treatment could significantly reduce alanine aminotransferase (ALT), hepatic steatosis and inflammation compared with placebo group, which indicates the good beneficial effect of resveratrol against fatty liver diseases [140-142]. One another group reported that resveratrol treated patients only showed a non-significant plasma ALT alleviation $(p=0.51)$ and a limited hepatic lipid content reduction (3.8\% decrease, $p=0.38$ ), but some serious adverse events were observed in 2 out of 14 patients during 6 months treatment [143]. On the contrary, according to the study from the fourth group, there were no beneficial effect of resveratrol on all the parameters that they examined related to liver injury, hepatic steatosis, insulin sensitivity and inflammation in NAFLD patients, instead, significantly increased hepatic stress was observed in patients under 6-month resveratrol administration [144]. These clinical trial results leave us a puzzling understanding on resveratrol effect requiring more examinations at clinical trial level to confirm it. In addition to the extensive effort on developing resveratrol to a clinically available drug for metabolic diseases treatment, two companies (Royal DSM Nutritional Products, Inc., Amsterdam, Netherlands and Resveratrol Partners LLC, Las Vegas, US) also applied an alternative way bringing resveratrol to be commercially available by reforming resveratrol to market-acceptable products, resVida ${ }^{\circledR}$ and Longevinex ${ }^{\circledR}$ respectively, as dietary and food ingredient for people with metabolic burdens to ameliorate their physical conditions.

\section{Conclusions and future aspects}

We have reviewed the latest advances on the roles of SIRT1 in maintaining normal liver development and functioning, as well as the beneficial effects of SIRT1 activation against fatty liver diseases by its activators. As summarized in figure 1 \& 2, SIRT1 plays important roles in regulating lipid metabolism, hepatic oxidative stress and inflammation in the liver. Activation of SIRT1 inhibits hepatic de novo lipogenesis by deacetylating SREBP-1c and ChREBP (Figure 1), increases fatty acid $\beta$-oxidation via deacetylating PPARa/PGC-1a (Figure 1), defends hepatic oxidative stress through enhancing antioxidant capability via deacetylating FOXOs and PGC-1a (Figure 2), and reduces local and circulating inflammation through deacetylating NF-kB in liver and adipose tissue (Figure 2). Based on evidences obtained from fatty liver mice treated with SIRT1 activators (Table 2) and from human clinical trials on SIRT1 activators against metabolic disorders, including fatty liver diseases (Table 3), activation of SIRT1 and its downstream signaling is very likely to serve as promising therapeutic approaches for the treatment of fatty liver diseases.

Although representative SIRT1 activators, like resveratrol and SRT501 (micronized resveratrol formulation developed by Sirtris Pharmaceuticals), are very promising for fatty liver diseases treatment and have been advanced to phase IV clinical trials for metabolic diseases, there are still some unsolvable limitations for them as clinical drugs, including inconsistent beneficial effects varying from independent trials [140-144], off-target problem caused by non-specific activation [129], serious side effect after long-term prescription (6 month) [143, $144]$, and significant poor bioavailability with rapid metabolism [130, 131]. Thus, further investigation on finding new SIRT1 activators with better safety and improved bioavailability is needed. In recent years, a series of potent SIRT1 agonists have been discovered from large-scale screening, and some of them are undergoing phase I \& II clinical trials, including SRT2104, SRT2379 and SRT3025 (Table 3). However, cautious evaluation on these newly developed SIRT1 agonists are still necessary to avoid any un-wanted side effects, especially for those later developed ones with 800-1000-fold more potency than resveratrol in activating SIRT1 [132]. Thus, for pharmacological application of SIRT1 activators, there are still a lot of emerging works to do, so as to ultimately utilize SIRT1 as a useful therapeutic target in fatty liver diseases and other metabolic diseases.

In addition to pharmacological concerns on SIRT1 activators, more extensive studies on diverse roles of SIRT1 activation in multi-organ level are also highly needed, such as in adipose tissue-liver axis. During fatty liver formation, fatty acid flux from adipose tissue to liver has been demonstrated as an important out-coming lipid source both in NAFLD and AFLD (Figure 2) [35, 40, 42]. As summarized in 
figure 2, SIRT1 activation promotes lipolysis in adipocytes and releases large amount of free fatty acids to circulation [145-147] which may induce or aggravate hepatic steatosis formation. So, it is risky to apply SIRT1 activating drugs for fatty liver diseases treatment without organ specificity, which might explain why inconsistent results occurred in several fatty liver diseases related clinical trials with resveratrol treatment [140-144]. In order to apply SIRT1 as a reliable therapeutic target for fatty liver and other metabolic diseases, we need to further extensively illuminate the diverse roles of SIRT1 in multi-organ level, especially in fatty liver diseases related adipose tissue-liver axis and pancreas-liver axis.

Table 3. Summary of clinical trials on SIRTI activators for fatty liver diseases and other metabolic diseases.

\begin{tabular}{|c|c|c|c|c|c|c|c|}
\hline & Study description & Phase & Identifier & Drugs & Diseases or Conditions & Status & Study period \\
\hline \multicolumn{8}{|c|}{ Studies on fatty liver diseases } \\
\hline 1 & $\begin{array}{l}\text { The effects of resveratrol on lipid profiles, liver enzymes, } \\
\text { inflammatory factors and hepatic fibrosis in nonalcoholic } \\
\text { steatohepatitis patients }\end{array}$ & $\begin{array}{l}\text { II \& } \\
\text { III }\end{array}$ & NCT02030977 & Resveratrol & NAFLD & Completed & Jun. 2012-Mar. 2013 \\
\hline 2 & $\begin{array}{l}\text { Safety and efficacy of resveratrol for the treatment of NAFLD and } \\
\text { associated insulin resistance in overweight and obese adolescents }\end{array}$ & $\begin{array}{l}\text { II \& } \\
\text { III }\end{array}$ & NCT02216552 & Resveratrol & NAFLD; Obesity & Recruiting & Aug. 2015- \\
\hline 3 & Resveratrol in patients with non-alcoholic fatty liver disease & - & NCT01464801 & Resveratrol & NAFLD & Completed & Sep.2011-Jun. 2015 \\
\hline 4 & $\begin{array}{l}\text { Evaluate the effects of resveratrol on liver fat content, body fat } \\
\text { distribution and insulin sensitivity }\end{array}$ & - & NCT01635114 & Resveratrol & $\begin{array}{l}\text { NAFLD; Insulin } \\
\text { resistance }\end{array}$ & Completed & Jun. 2012-Sep. 2015 \\
\hline 5 & $\begin{array}{l}\text { Long-term investigation of resveratrol on lipid turnover in obese } \\
\text { men with NAFLD }\end{array}$ & - & NCT01446276 & Resveratrol & NAFLD; Obesity & Completed & Nov.2011-Apr. 2014 \\
\hline \multicolumn{8}{|c|}{ Studies on metabolic diseases (disorders) associated inflammation and/or oxidative stress } \\
\hline 6 & $\begin{array}{l}\text { Effects of resveratrol on inflammation and oxidative stress of } \\
\text { non-dialysis chronic kidney diseases patients }\end{array}$ & III & NCT02433925 & Resveratrol & $\begin{array}{l}\text { Chronic renal } \\
\text { insufficiency }\end{array}$ & Completed & Jan. 2013-Dec. 2014 \\
\hline 7 & $\begin{array}{l}\text { Anti-inflammatory and antioxidant effects of resveratrol on } \\
\text { healthy adults }\end{array}$ & III & NCT01492114 & Resveratrol & Healthy volunteer & Completed & Jul. 2011-Mar. 2012 \\
\hline 8 & Effects of resveratrol on inflammation in type 2 diabetic patients & III & NCT02244879 & Resveratrol & Type 2 diabetes & Completed & Oct 2013-Feb. 2016 \\
\hline 9 & $\begin{array}{l}\text { Effect of resveratrol on insulin resistance and inflammatory } \\
\text { mediators in obese and type } 2 \text { diabetic subjects }\end{array}$ & $\begin{array}{l}\text { II \& } \\
\text { III }\end{array}$ & NCT01158417 & Resveratrol & $\begin{array}{l}\text { Type } 2 \text { diabetes; } \\
\text { Obesity }\end{array}$ & Unknown & Dec. 2008- \\
\hline 10 & $\begin{array}{l}\text { Effect of resveratrol on age-related insulin resistance and } \\
\text { inflammation in humans }\end{array}$ & II & NCT01354977 & Resveratrol & $\begin{array}{l}\text { Type } 2 \text { diabetes; } \\
\text { Insulin resistance }\end{array}$ & Unknown & Mar. 2008- \\
\hline 11 & $\begin{array}{l}\text { The effects of trans-resveratrol on insulin resistance, inflammation, } \\
\text { and the metabolic syndrome }\end{array}$ & II & NCT01714102 & Resveratrol & $\begin{array}{l}\text { Obesity; Insulin } \\
\text { resistance }\end{array}$ & $\begin{array}{l}\text { Active, not } \\
\text { recruiting }\end{array}$ & Oct. 2012- \\
\hline 12 & $\begin{array}{l}\text { A phase I dose-ranging study to evaluate the activity of SRT2379 } \\
\text { on endotoxin induced inflammatory response in healthy male } \\
\text { subjects }\end{array}$ & I & NCT01416376 & SRT2379 & $\begin{array}{l}\text { Healthy volunteer } \\
\text { treated with LPS }\end{array}$ & Completed & Aug. 2011-Dec. 2011 \\
\hline 13 & $\begin{array}{l}\text { A phase I study to evaluate a single oral dose of SRT } 2379 \text { on the } \\
\text { endotoxin induced inflammatory response in healthy male subjects }\end{array}$ & I & NCT01262911 & SRT2379 & $\begin{array}{l}\text { Healthy volunteer } \\
\text { treated with LPS }\end{array}$ & Completed & Feb. 2011-Apr. 2011 \\
\hline 14 & $\begin{array}{l}\text { A phase I study to evaluate multiple oral doses of SRT } 2104 \text { on the } \\
\text { endotoxin induced inflammatory response in healthy male subjects }\end{array}$ & I & NCT01014117 & SRT2104 & $\begin{array}{l}\text { Healthy volunteer } \\
\text { treated with LPS }\end{array}$ & Completed & Dec. 2009-May. 2010 \\
\hline 15 & $\begin{array}{l}\text { Long-term investigation of resveratrol on management of } \\
\text { metabolic syndrome, osteoporosis and inflammation }\end{array}$ & - & NCT01412645 & Resveratrol & Metabolic syndrome & Completed & Aug. 2011-Aug. 2013 \\
\hline 16 & $\begin{array}{l}\text { The effects of resveratrol supplementation on measurements of } \\
\text { health and human performance }\end{array}$ & - & NCT01244360 & Resveratrol & Healthy volunteer & Unknown & Nov. 2010- \\
\hline 17 & $\begin{array}{l}\text { Potential beneficial effects of resveratrol on obesity, metabolic } \\
\text { syndrome and inflammation }\end{array}$ & - & NCT01150955 & Resveratrol & $\begin{array}{l}\text { Metabolic syndrome; } \\
\text { Obesity }\end{array}$ & Completed & Oct. 2010-Nov. 2011 \\
\hline \multicolumn{8}{|c|}{ Studies on other metabolic diseases (disorders) at phase IV } \\
\hline 18 & $\begin{array}{l}\text { Effect of resveratrol on improving insulin sensitivity and } \\
\text { preserving beta cell function following gestational diabetes }\end{array}$ & IV & NCT01997762 & Resveratrol & Gestational diabetes & Unknown & May 2014- \\
\hline 19 & $\begin{array}{l}\text { Effects of simvastatin and micronized trans-resveratrol treatment } \\
\text { on polycystic ovary syndrome (PCOS) patients }\end{array}$ & IV & NCT02766803 & $\begin{array}{l}\text { SRT501; } \\
\text { Simvastatin }\end{array}$ & $\begin{array}{l}\text { PCOS; Insulin } \\
\text { resistance }\end{array}$ & Recruiting & May 2016- \\
\hline \multicolumn{8}{|c|}{ Studies on other newly developed potent SIRT1 activators } \\
\hline 20 & $\begin{array}{l}\text { A phase II study to assess the safety, tolerability, and activity of } \\
\text { oral SRT2104 capsules administered in type } 2 \text { diabetes subjects }\end{array}$ & II & NCT01018017 & SRT2104 & Type 2 diabetes & Completed & Mar. 2010-Dec. 2010 \\
\hline 21 & $\begin{array}{l}\text { A phase II study to assess the safety and pharmacokinetics of } \\
\text { SRT2104 in type } 2 \text { diabetic human subjects }\end{array}$ & II & NCT00937326 & SRT2104 & Type 2 diabetes & Completed & Aug. 2009-Sep. 2010 \\
\hline 22 & $\begin{array}{l}\text { A phase I study in healthy male volunteers to investigate different } \\
\text { doses of SRT3025 for the treatment of metabolic diseases }\end{array}$ & I & NCT01340911 & SRT3025 & Healthy volunteer & Completed & Jun. 2011-Feb. 2012 \\
\hline 23 & $\begin{array}{l}\text { A phase I study to assess the pharmacokinetics of SRT2104 } \\
\text { administered as an oral suspension or capsule formulation to } \\
\text { normal healthy volunteers }\end{array}$ & I & NCT00938275 & SRT2104 & Healthy volunteer & Completed & Jan. 2009-Mar. 2009 \\
\hline 24 & $\begin{array}{l}\text { A phase I study to assess the pharmacokinetics, safety and } \\
\text { tolerability of SRT } 2104 \text { administered to normal healthy male } \\
\text { volunteers }\end{array}$ & I & NCT00933062 & SRT2104 & Healthy volunteer & Completed & Mar. 2009-May 2009 \\
\hline 25 & $\begin{array}{l}\text { Evaluation of the pharmacokinetics and the absolute } \\
\text { bioavailability of SRT } 2104 \text { in healthy male subjects }\end{array}$ & I & NCT00937872 & SRT2104 & Healthy volunteer & Completed & Nov. 2008-Dec. 2008 \\
\hline 26 & $\begin{array}{l}\text { A phase I study to assess the safety of oral SRT } 2104 \text { and its effects } \\
\text { on vascular dysfunction in healthy and type } 2 \text { diabetes subjects }\end{array}$ & I & NCT01031108 & SRT2104 & Type 2 diabetes & Completed & May 2010-Oct. 2011 \\
\hline 27 & $\begin{array}{l}\text { A phase I study to assess the safety and pharmacokinetics of } \\
\text { SRT2104 in normal healthy male volunteers }\end{array}$ & I & NCT00933530 & SRT2104 & Healthy volunteer & Completed & May 2008-Nov. 2008 \\
\hline 28 & $\begin{array}{l}\text { A phase I study to assess the safety and pharmacokinetics of } \\
\text { SRT2379 in normal healthy male volunteers }\end{array}$ & I & NCT01018628 & SRT2379 & Healthy volunteer & Completed & Dec. 2009-Aug. 2010 \\
\hline
\end{tabular}


Since fatty liver diseases always encompass a continued spectrum of liver damages that might advance to liver cancer in some cases, future efforts will also be delivered toward the interplays among SIRT1, fatty liver and cancer. It is noteworthy to indicate that the roles of SIRT1 in liver cancer are controversial. In some reports, SIRT1 protein expression was significantly overexpressed as compared with adjacent non-tumor liver tissues, and the elevated SIRT1 levels are correlated with cancer grades and predicted poor prognosis [148-150]. However, in other reports it was also shown that 2-fold reduction of SIRT1 protein levels were displayed in 46 of 263 hepatocellular carcinoma tumors when compared to their normal controls [151] and activation of SIRT1 resulted in antitumor effect in liver cancer [152-155]. As the controversy over whether SIRT1 is a tumor suppressor or oncogene remains unsolved [8], it needs to be cautious on fatty liver patients with cancer complications when treating with SIRT1 activators, and to be paid more effort on elucidating SIRT1 roles among different degrees of liver diseases (e.g. fatty liver and liver cancer) and different types of diseases.

\section{Acknowledgements}

We thank members of the Deng laboratory for critical reading and discussion. This work is supported by the Chair Professor Grant (CPG2017-00026-FHS), Startup Research Grant (SRG2015-00045-FHS), MYRG2016-00132-FHS and MYRG2016-00139 of University of Macau and FDCT grants (065/2015/A2 and 094/2015/A3) to Chu-Xia Deng.

\section{Competing Interests}

The authors have declared that no competing interest exists.

\section{References}

1. Paschos P, Paletas K. Non alcoholic fatty liver disease and metabolic syndrome. Hippokratia. 2009; 13: 9-19.

2. Kufre Effiong AO, Andy Pring, Julia Verne. Deaths from Liver Disease. Implications for End of Life Care in England. Bristol, UK: National End of Life Care Intelligence Network; 2012.

3. Postic C, Girard J. Contribution of de novo fatty acid synthesis to hepatic steatosis and insulin resistance: lessons from genetically engineered mice. J Clin Invest. 2008; 118: 829-38.

4. Ding RB, Tian K, Huang LL, He CW, Jiang Y, Wang YT, et al. Herbal medicines for the prevention of alcoholic liver disease: a review. J Ethnopharmacol. 2012; 144: 457-65.

5. Colak Y, Yesil A, Mutlu HH, Caklili OT, Ulasoglu C, Senates E, et al. A potential treatment of non-alcoholic fatty liver disease with SIRT1 activators. J Gastrointestin Liver Dis. 2014; 23: 311-9.

6. Li X. SIRT1 and energy metabolism. Acta Biochim Biophys Sin (Shanghai). 2013; 45: 51-60.

7. Finkel T, Deng CX, Mostoslavsky R. Recent progress in the biology and physiology of sirtuins. Nature. 2009; 460: 587-91.

8. Deng CX. SIRT1, is it a tumor promoter or tumor suppressor? Int J Biol Sci. 2009; 5: 147-52

9. Mei Z, Zhang X, Yi J, Huang J, He J, Tao Y. Sirtuins in metabolism, DNA repair and cancer. J Exp Clin Cancer Res. 2016; 35: 182.
10. Vachharajani VT, Liu T, Wang $X$, Hoth JJ, Yoza BK, McCall CE. Sirtuins Link Inflammation and Metabolism. J Immunol Res. 2016; 2016: 8167273.

11. Santos L, Escande C, Denicola A. Potential Modulation of Sirtuins by Oxidative Stress. Oxid Med Cell Longev. 2016; 2016: 9831825.

12. Wang RH, Zhao TR, Cui KR, Hu GQ, Chen Q, Chen WP, et al. Negative reciprocal regulation between Sirt1 and Per2 modulates the circadian clock and aging. Sci Rep-Uk. 2016; 6: 28633

13. Jeong SM, Xiao CY, Finley LWS, Lahusen T, Souza AL, Pierce K, et al. SIRT4 Has Tumor-Suppressive Activity and Regulates the Cellular Metabolic Response to DNA Damage by Inhibiting Mitochondrial Glutamine Metabolism. Cancer Cell. 2013; 23: 450-63.

14. Xiao CY, Wang RH, Lahusen TJ, Park O, Bertola A, Maruyama T, et al. Progression of Chronic Liver Inflammation and Fibrosis Driven by Activation of c-JUN Signaling in Sirt6 Mutant Mice. J Biol Chem. 2012; 287: 41903-13.

15. Kim HS, Vassilopoulos A, Wang RH, Lahusen T, Xiao Z, Xu XL, et al. SIRT2 Maintains Genome Integrity and Suppresses Tumorigenesis through Regulating APC/C Activity. Cancer Cell. 2011; 20: 487-99.

16. Li X, Kazgan N. Mammalian sirtuins and energy metabolism. Int J Biol Sci. 2011; 7: 575-87.

17. Wang RH, Lahusen TJ, Chen $\mathrm{Q}, \mathrm{Xu} \mathrm{X}$, Jenkins LM, Leo E, et al. SIRT1 deacetylates TopBP1 and modulates intra-S-phase checkpoint and DNA replication origin firing. Int J Biol Sci. 2014; 10: 1193-202.

18. Chaudhary N, Pfluger PT. Metabolic benefits from Sirt1 and Sirt1 activators. Curr Opin Clin Nutr Metab Care. 2009; 12: 431-7.

19. Lalla R, Donmez G. The role of sirtuins in Alzheimer's disease. Front Aging Neurosci. 2013; 5: 16

20. Pulla VK, Battu MB, Alvala M, Sriram D, Yogeeswari P. Can targeting SIRT-1 to treat type 2 diabetes be a good strategy? A review. Expert Opin Ther Targets. 2012; 16: 819-32.

21. Cho EH. SIRT3 as a Regulator of Non-alcoholic Fatty Liver Disease. Journal of lifestyle medicine. 2014; 4: 80-5.

22. Nassir F, Ibdah JA. Sirtuins and nonalcoholic fatty liver disease. World J Gastroenterol. 2016; 22: 10084-92.

23. Kim HS, Xiao C, Wang RH, Lahusen $\mathrm{T}, \mathrm{Xu} X$, Vassilopoulos A, et al. Hepatic-specific disruption of SIRT6 in mice results in fatty liver formation due to enhanced glycolysis and triglyceride synthesis. Cell metabolism. 2010; 12: 224-36.

24. Wu T, Liu $\mathrm{YH}, \mathrm{Fu} \mathrm{YC}$, Liu XM, Zhou $\mathrm{XH}$. Direct evidence of sirtuin downregulation in the liver of non-alcoholic fatty liver disease patients. Ann Clin Lab Sci. 2014; 44: 410-8.

25. Tarantino G, Finelli C, Scopacasa F, Pasanisi F, Contaldo F, Capone D, et al. Circulating levels of sirtuin 4, a potential marker of oxidative metabolism, related to coronary artery disease in obese patients suffering from NAFLD, with normal or slightly increased liver enzymes. Oxid Med Cell Longev. 2014; 2014: 920676.

26. Kendrick AA, Choudhury M, Rahman SM, McCurdy CE, Friederich M, Van Hove JL, et al. Fatty liver is associated with reduced SIRT3 activity and mitochondrial protein hyperacetylation. Biochem J. 2011; 433: 505-14.

27. Xu F, Gao Z, Zhang J, Rivera CA, Yin J, Weng J, et al. Lack of SIRT1 (Mammalian Sirtuin 1) activity leads to liver steatosis in the SIRT1+/- mice: a role of lipid mobilization and inflammation. Endocrinology. 2010; 151: 2504-14.

28. Purushotham A, Schug TT, Xu Q, Surapureddi S, Guo X, Li X. Hepatocyte-specific deletion of SIRT1 alters fatty acid metabolism and results in hepatic steatosis and inflammation. Cell Metab. 2009; 9: 327-38.

29. Yin H, Hu M, Liang X, Ajmo JM, Li X, Bataller R, et al. Deletion of SIRT1 from hepatocytes in mice disrupts lipin-1 signaling and aggravates alcoholic fatty liver. Gastroenterology. 2014; 146: 801-11.

30. Pfluger PT, Herranz D, Velasco-Miguel S, Serrano M, Tschop MH. Sirt1 protects against high-fat diet-induced metabolic damage. Proc Natl Acad Sci U S A. 2008; 105: 9793-8.

31. You M, Jogasuria A, Taylor $\mathrm{C}, \mathrm{Wu}$ J. Sirtuin 1 signaling and alcoholic fatty liver disease. Hepatobiliary Surg Nutr. 2015; 4: 88-100.

32. Colak Y, Ozturk O, Senates E, Tuncer I, Yorulmaz E, Adali G, et al. SIRT1 as a potential therapeutic target for treatment of nonalcoholic fatty liver disease. Med Sci Monit. 2011; 17: Hy5-9.

33. Ahn J, Cho I, Kim S, Kwon D, Ha T. Dietary resveratrol alters lipid metabolism-related gene expression of mice on an atherogenic diet. J Hepatol. 2008; 49: 1019-28.

34. Li H, Xu M, Lee J, He C, Xie Z. Leucine supplementation increases SIRT1 expression and prevents mitochondrial dysfunction and metabolic disorders in high-fat diet-induced obese mice. Am J Physiol Endocrinol Metab. 2012; 303: E1234-44.

35. Cohen JC, Horton JD, Hobbs HH. Human fatty liver disease: old questions and new insights. Science. 2011; 332: 1519-23.

36. Purohit V, Gao B, Song BJ. Molecular mechanisms of alcoholic fatty liver. Alcohol Clin Exp Res. 2009; 33: 191-205.

37. Redgrave TG. Formation of cholesteryl ester-rich particulate lipid during metabolism of chylomicrons. J Clin Invest. 1970; 49: 465-71.

38. Horton JD, Goldstein JL, Brown MS. SREBPs: activators of the complete program of cholesterol and fatty acid synthesis in the liver. J Clin Invest. 2002; 109: 1125-31

39. Uyeda K, Repa JJ. Carbohydrate response element binding protein, ChREBP, a transcription factor coupling hepatic glucose utilization and lipid synthesis. Cell Metab. 2006; 4: 107-10. 
40. Ding RB, Tian K, Cao YW, Bao JL, Wang M, He C, et al. Protective effect of panax notoginseng saponins on acute ethanol-induced liver injury is associated with ameliorating hepatic lipid accumulation and reducing ethanol-mediated oxidative stress. J Agric Food Chem. 2015; 63: 2413-22.

41. Zhong W, Zhao Y, Tang Y, Wei X, Shi X, Sun W, et al. Chronic alcohol exposure stimulates adipose tissue lipolysis in mice: role of reverse triglyceride transport in the pathogenesis of alcoholic steatosis. Am J Pathol. 2012; 180: 998-1007.

42. Ding RB, Bao JL, Cao YW, He C, Wang YT, Wan JB. Panax notoginseng saponins protect against chronic ethanol-induced hepatic steatosis. J Chin Pharm Sci. 2014; 23: 361-8.

43. Ferre P, Foufelle F. Hepatic steatosis: a role for de novo lipogenesis and the transcription factor SREBP-1c. Diabetes Obes Metab. 2010; 12: 83-92.

44. Argo CK, Northup PG, Al-Osaimi AM, Caldwell SH. Systematic review of risk factors for fibrosis progression in non-alcoholic steatohepatitis. J Hepatol. 2009; 51: 371-9.

45. Argo CK, Caldwell SH. Epidemiology and natural history of non-alcoholic steatohepatitis. Clin Liver Dis. 2009; 13: 511-31.

46. Feldstein AE, Bailey SM. Emerging role of redox dysregulation in alcoholic and nonalcoholic fatty liver disease. Antioxid Redox Signal. 2011; 15: 421-4.

47. Liu WS, Baker RD, Bhatia T, Zhu LX, Baker SS. Pathogenesis of nonalcoholic steatohepatitis. Cell Mol Life Sci. 2016; 73: 1969-87.

48. Caligiuri A, Gentilini A, Marra F. Molecular Pathogenesis of NASH. Int J Mol Sci. 2016; 17: 1575

49. Kema VH, Mojerla NR, Khan I, Mandal P. Effect of alcohol on adipose tissue: a review on ethanol mediated adipose tissue injury. Adipocyte. 2015; 4: 225-31.

50. van der Heijden RA, Sheedfar F, Morrison MC, Hommelberg PPH, Kor D, Kloosterhuis NJ, et al. High-fat diet induced obesity primes inflammation in adipose tissue prior to liver in C57BL/6j mice. Aging-Us. 2015; 7: 256-68.

51. du Plessis J, van Pelt J, Korf H, Mathieu C, van der Schueren B, Lannoo M, et al. Association of Adipose Tissue Inflammation With Histologic Severity of Nonalcoholic Fatty Liver Disease. Gastroenterology. 2015; 149: 635-48.

52. Stanton MC, Chen SC, Jackson JV, Rojas-Triana A, Kinsley D, Cui L, et al. Inflammatory Signals shift from adipose to liver during high fat feeding and influence the development of steatohepatitis in mice. J Inflammation. 2011; 8: 8.

53. Sinclair DA, Guarente L. Extrachromosomal rDNA circles--a cause of aging in yeast. Cell. 1997; 91: 1033-42.

54. Fiorino E, Giudici M, Ferrari A, Mitro N, Caruso D, De Fabiani E, et al. The sirtuin class of histone deacetylases: regulation and roles in lipid metabolism. IUBMB Life. 2014; 66: 89-99.

55. Xie J, Zhang XM, Zhang L. Negative regulation of inflammation by SIRT1. Pharmacol Res. 2013; 67: 60-7.

56. Rajamohan SB, Pillai VB, Gupta M, Sundaresan NR, Birukov KG, Samant S, et al. SIRT1 promotes cell survival under stress by deacetylation-dependent deactivation of poly(ADP-ribose) polymerase 1. Mol Cell Biol. 2009; 29: 4116-29.

57. Simmons GE, Pruitt WM, Pruitt K. Diverse Roles of SIRT1 in Cancer Biology and Lipid Metabolism. Int J Mol Sci. 2015; 16: 950-65.

58. Guclu A, Erdur FM, Turkmen K. The Emerging Role of Sirtuin 1 in Cellular Metabolism, Diabetes Mellitus, Diabetic Kidney Disease and Hypertension. Exp Clin Endocrinol Diabetes. 2016; 124: 131-9.

59. Ramirez T, Li YM, Yin S, Xu MJ, Feng D, Zhou Z, et al. Aging aggravates alcoholic liver injury and fibrosis in mice by downregulating sirtuin 1 expression. J Hepatol. 2017; 66: 601-9.

60. Zakhari S. Alcohol metabolism and epigenetics changes. Alcohol research : current reviews. 2013; 35: 6-16.

61. Zakhari S. Overview: How is alcohol metabolized by the body? Alcohol Res Health. 2006; 29: 245-54.

62. Deng XQ, Chen LL, Li NX. The expression of SIRT1 in nonalcoholic fatty liver disease induced by high-fat diet in rats. Liver Int. 2007; 27: 708-15.

63. Ahn J, Lee H, Jung CH, Ha TY, Jang YJ. Effect of a new dietary SIRT1 activator on high fat diet-induced obesity and the involvement of microRNAs. FASEB J. $2015 ; 29$.

64. Baur JA, Pearson KJ, Price NL, Jamieson HA, Lerin C, Kalra A, et al. Resveratrol improves health and survival of mice on a high-calorie diet. Nature. 2006; 444: 337-42.

65. Michan S, Sinclair D. Sirtuins in mammals: insights into their biological function. Biochem J. 2007; 404: 1-13.

66. Wang Y. Molecular Links between Caloric Restriction and Sir2/SIRT1 Activation. Diabetes Metab J. 2014; 38: 321-9.

67. Chen D, Bruno J, Easlon E, Lin SJ, Cheng HL, Alt FW, et al. Tissue-specific regulation of SIRT1 by calorie restriction. Genes Dev. 2008; 22: 1753-7.

68. Wang RH, Li C, Deng CX. Liver steatosis and increased ChREBP expression in mice carrying a liver specific SIRT1 null mutation under a normal feeding condition. Int J Biol Sci. 2010; 6: 682-90.

69. Wang RH, Kim HS, Xiao C, Xu X, Gavrilova O, Deng CX. Hepatic Sirt1 deficiency in mice impairs mTorc2/Akt signaling and results in hyperglycemia, oxidative damage, and insulin resistance. J Clin Invest. 2011; 121: 4477-90.

70. Tobita T, Guzman-Lepe J, Takeishi K, Nakao T, Wang Y, Meng F, et al. SIRT1 Disruption in Human Fetal Hepatocytes Leads to Increased Accumulation of Glucose and Lipids. PLoS One. 2016; 11: e0149344.

71. Strable MS, Ntambi JM. Genetic control of de novo lipogenesis: role in diet-induced obesity. Crit Rev Biochem Mol Biol. 2010; 45: 199-214.
72. Walker AK, Naar AM SREBPs: regulators of cholesterol/lipids as therapeutic targets in metabolic disorders, cancers and viral diseases. Clin Lipidol. 2012; 7 : 27-36.

73. Horton JD. Sterol regulatory element-binding proteins: transcriptional activators of lipid synthesis. Biochem Soc Trans. 2002; 30: 1091-5.

74. Kemper JK, Choi SE, Kim DH. Sirtuin 1 deacetylase: a key regulator of hepatic lipid metabolism. Vitam Horm. 2013; 91: 385-404.

75. Ponugoti B, Kim DH, Xiao Z, Smith Z, Miao J, Zang M, et al. SIRT1 deacetylates and inhibits SREBP-1C activity in regulation of hepatic lipid metabolism. J Biol Chem. 2010; 285: 33959-70.

76. Walker AK, Yang F, Jiang K, Ji JY, Watts JL, Purushotham A, et al. Conserved role of SIRT1 orthologs in fasting-dependent inhibition of the lipid/cholesterol regulator SREBP. Genes Dev. 2010; 24: 1403-17.

77. Giandomenico V, Simonsson M, Gronroos E, Ericsson J. Coactivator-dependent acetylation stabilizes members of the SREBP family of transcription factors. Mol Cell Biol. 2003; 23: 2587-99.

78. Andrade JM, Paraiso AF, de Oliveira MV, Martins AM, Neto JF, Guimaraes $\mathrm{AL}$, et al. Resveratrol attenuates hepatic steatosis in high-fat fed mice by decreasing lipogenesis and inflammation. Nutrition. 2014; 30: 915-9.

79. Alberdi G, Rodriguez VM, Macarulla MT, Miranda J, Churruca I, Portillo MP. Hepatic lipid metabolic pathways modified by resveratrol in rats fed an obesogenic diet. Nutrition. 2013; 29: 562-7.

80. Gariani K, Menzies KJ, Ryu D, Wegner CJ, Wang X, Ropelle ER, et al. Eliciting the mitochondrial unfolded protein response by nicotinamide adenine dinucleotide repletion reverses fatty liver disease in mice. Hepatology. 2016; 63: 1190-204

81. You M, Liang X, Ajmo JM, Ness GC. Involvement of mammalian sirtuin 1 in the action of ethanol in the liver. Am J Physiol Gastrointest Liver Physiol. 2008; 294: G892-8.

82. Ajmo JM, Liang X, Rogers CQ, Pennock B, You M. Resveratrol alleviates alcoholic fatty liver in mice. Am J Physiol Gastrointest Liver Physiol. 2008; 295 : G833-42.

83. Bricambert J, Miranda J, Benhamed F, Girard J, Postic C, Dentin R. Salt-inducible kinase 2 links transcriptional coactivator p300 phosphorylation to the prevention of ChREBP-dependent hepatic steatosis in mice. J Clin Invest. 2010; 120: 4316-31.

84. Filhoulaud G, Guilmeau S, Dentin R, Girard J, Postic C. Novel insights into ChREBP regulation and function. Trends Endocrinol Metab. 2013 : 24: 257-68.

85. Marmier S, Dentin R, Loterstazjn S, Postic C. Role of ChREBP in liver alcoholic steatosis development. J Hepatol. 2013; 58: S53.

86. Marmier S, Dentin R, Daujat-Chavanieu M, Guillou H, Bertrand-Michel J, Gerbal-Chaloin S, et al. Novel role for carbohydrate responsive element binding protein in the control of ethanol metabolism and susceptibility to binge drinking. Hepatology. 2015; 62: 1086-100.

87. Yang SJ, Lim Y. Resveratrol ameliorates hepatic metaflammation and inhibits NLRP3 inflammasome activation. Metabolism. 2014; 63: 693-701.

88. Francis GA, Fayard E, Picard F, Auwerx J. Nuclear receptors and the control of metabolism. Annu Rev Physiol. 2003; 65: 261-311.

89. Lomb DJ, Laurent G, Haigis MC. Sirtuins regulate key aspects of lipid metabolism. Biochim Biophys Acta. 2010; 1804: 1652-7.

90. Rodgers JT, Lerin C, Haas W, Gygi SP, Spiegelman BM, Puigserver P. Nutrient control of glucose homeostasis through a complex of PGC-1alpha and SIRT1. Nature. 2005; 434: 113-8.

91. Li S, Liu C, Li N, Hao T, Han T, Hill DE, et al. Genome-wide coactivation analysis of PGC-1alpha identifies BAF60a as a regulator of hepatic lipid metabolism. Cell metabolism. 2008; 8: 105-17.

92. Rodgers JT, Puigserver P. Fasting-dependent glucose and lipid metabolic response through hepatic sirtuin 1. Proc Natl Acad Sci U S A. 2007; 104: 12861-6.

93. Feige JN, Lagouge M, Canto C, Strehle A, Houten SM, Milne JC, et al. Specific SIRT1 activation mimics low energy levels and protects against diet-induced metabolic disorders by enhancing fat oxidation. Cell metabolism. 2008; 8: 347-58.

94. Lagouge M, Argmann C, Gerhart-Hines Z, Meziane H, Lerin C, Daussin F, et al. Resveratrol improves mitochondrial function and protects against metabolic disease by activating SIRT1 and PGC-1alpha. Cell. 2006; 127: 1109-22.

95. Everitt $\mathrm{H}, \mathrm{Hu} \mathrm{M}$, Ajmo JM, Rogers $\mathrm{CQ}$, Liang $\mathrm{X}$, Zhang $\mathrm{R}$, et al. Ethanol administration exacerbates the abnormalities in hepatic lipid oxidation in genetically obese mice. Am J Physiol Gastrointest Liver Physiol. 2013; 304: G38-47.

96. Lieber CS, Leo MA, Wang X, Decarli LM. Effect of chronic alcohol consumption on Hepatic SIRT1 and PGC-1alpha in rats. Biochem Biophys Res Commun. 2008; 370: 44-8

97. Aroor AR, Mandavia C, Ren J, Sowers JR, Pulakat L. Mitochondria and Oxidative Stress in the Cardiorenal Metabolic Syndrome. Cardiorenal Med. 2012; 2: 87-109.

98. Ji LL. Antioxidants and oxidative stress in exercise. Proc Soc Exp Biol Med. 1999; 222: 283-92.

99. Weir EK, Archer SL. The role of redox changes in oxygen sensing. Respir Physiol Neurobiol. 2010; 174: 182-91.

100. St-Pierre J, Drori S, Uldry M, Silvaggi JM, Rhee J, Jager S, et al. Suppression of reactive oxygen species and neurodegeneration by the PGC-1 transcriptional coactivators. Cell. 2006; 127: 397-408. 
101. Radak Z, Koltai E, Taylor AW, Higuchi M, Kumagai S, Ohno H, et al. Redox-regulating sirtuins in aging, caloric restriction, and exercise. Free Radic Biol Med. 2013; 58: 87-97.

102. Brunet A, Sweeney LB, Sturgill JF, Chua KF, Greer PL, Lin Y, et al. Stress-dependent regulation of FOXO transcription factors by the SIRT1 deacetylase. Science. 2004; 303: 2011-5.

103. van der Horst A, Tertoolen LGI, de Vries-Smits LMM, Frye RA, Medema RH, Burgering BMT. FOXO4 is acetylated upon peroxide stress and deacetylated by the longevity protein hSir2(SIRT1). J Biol Chem. 2004; 279: 28873-9.

104. Hori YS, Kuno A, Hosoda R, Horio Y. Regulation of FOXOs and p53 by SIRT1 modulators under oxidative stress. PLoS One. 2013; 8: e73875.

105. Li M, Guo K, Vanella L, Taketani S, Adachi Y, Ikehara S. Stem cell transplantation upregulates Sirt1 and antioxidant expression, ameliorating fatty liver in type 2 diabetic mice. Int J Biol Sci. 2015; 11: 472-81.

106. Canto C, Houtkooper RH, Pirinen E, Youn DY, Oosterveer MH, Cen Y, et al. The $\mathrm{NAD}(+)$ precursor nicotinamide riboside enhances oxidative metabolism and protects against high-fat diet-induced obesity. Cell metabolism. 2012; 15 : 838-47.

107. Bujanda L, Hijona E, Larzabal M, Beraza M, Aldazabal P, Garcia-Urkia N, et al. Resveratrol inhibits nonalcoholic fatty liver disease in rats. BMC Gastroenterol. 2008; 8: 40.

108. Tak PP, Firestein GS. NF-kappaB: a key role in inflammatory diseases. J Clin Invest. 2001; 107: 7-11.

109. Pillarisetti S. A review of Sirt1 and Sirt1 modulators in cardiovascular and metabolic diseases. Recent Pat Cardiovasc Drug Discov. 2008; 3: 156-64.

110. Baldwin AS, Jr. The NF-kappa B and I kappa B proteins: new discoveries and insights. Annu Rev Immunol. 1996; 14: 649-83.

111. Hoffmann A, Natoli G, Ghosh G. Transcriptional regulation via the NF-kappaB signaling module. Oncogene. 2006; 25: 6706-16.

112. Yeung F, Hoberg JE, Ramsey CS, Keller MD, Jones DR, Frye RA, et al. Modulation of NF-kappaB-dependent transcription and cell survival by the SIRT1 deacetylase. EMBO J. 2004; 23: 2369-80.

113. Shen Z, Ajmo JM, Rogers CQ, Liang X, Le L, Murr MM, et al. Role of SIRT1 in regulation of LPS- or two ethanol metabolites-induced TNF-alpha production in cultured macrophage cell lines. Am J Physiol Gastrointest Liver Physiol. 2009; 296: G1047-53.

114. Schug TT, Xu Q, Gao H, Peres-da-Silva A, Draper DW, Fessler MB, et al. Myeloid deletion of SIRT1 induces inflammatory signaling in response to environmental stress. Mol Cell Biol. 2010; 30: 4712-21.

115. Jeon BT, Kim KE, Heo RW, Shin HJ, Yi CO, Hah YS, et al. Myeloid-specific deletion of SIRT1 increases hepatic steatosis and hypothalamic inflammation in mice fed a high-fat diet. Metab Brain Dis. 2014; 29: 635-43.

116. Tian Y, Ma J, Wang W, Zhang L, Xu J, Wang K, et al. Resveratrol supplement inhibited the NF-kappaB inflammation pathway through activating AMPKalpha-SIRT1 pathway in mice with fatty liver. Mol Cell Biochem. 2016; 422: 75-84

117. Gillum MP, Kotas ME, Erion DM, Kursawe R, Chatterjee P, Nead KT, et al. SirT1 regulates adipose tissue inflammation. Diabetes. 2011; 60: 3235-45.

118. Kitada M, Kume S, Takeda-Watanabe A, Kanasaki K, Koya D. Sirtuins and renal diseases: relationship with aging and diabetic nephropathy. Clin Sci (Lond). 2013; 124: 153-64.

119. Howitz KT, Bitterman KJ, Cohen HY, Lamming DW, Lavu S, Wood JG, et al. Small molecule activators of sirtuins extend Saccharomyces cerevisiae lifespan. Nature. 2003; 425: 191-6.

120. Shang J, Chen LL, Xiao FX, Sun H, Ding HC, Xiao H. Resveratrol improves non-alcoholic fatty liver disease by activating AMP-activated protein kinase. Acta Pharmacol Sin. 2008; 29: 698-706.

121. Jin SH, Yang JH, Shin BY, Seo K, Shin SM, Cho IJ, et al. Resveratrol inhibits LXR alpha-dependent hepatic lipogenesis through novel antioxidant Sestrin2 gene induction. Toxicol Appl Pharmacol. 2013; 271: 95-105.

122. Choi YH, Bae JK, Chae HS, Kim YM, Sreymom Y, Han L, et al. alpha-Mangostin Regulates Hepatic Steatosis and Obesity through SirT1-AMPK and PPARgamma Pathways in High-Fat Diet-Induced Obese Mice. J Agric Food Chem. 2015; 63: 8399-406.

123. Shan W, Gao L, Zeng W, Hu Y, Wang G, Li M, et al. Activation of the SIRT1/p66shc antiapoptosis pathway via carnosic acid-induced inhibition of miR-34a protects rats against nonalcoholic fatty liver disease. Cell Death Dis. 2015; 6: e1833

124. Kim E, Choi Y, Jang J, Park T. Carvacrol Protects against Hepatic Steatosis in Mice Fed a High-Fat Diet by Enhancing SIRT1-AMPK Signaling. Evid Based Complement Alternat Med. 2013; 2013: 290104.

125. Santamarina AB, Oliveira JL, Silva FP, Carnier J, Mennitti LV, Santana AA, et al. Green Tea Extract Rich in Epigallocatechin-3-Gallate Prevents Fatty Liver by AMPK Activation via LKB1 in Mice Fed a High-Fat Diet. PLoS One. 2015; 10: $\mathrm{e} 0141227$.

126. Zeng W, Shan W, Gao L, Gao D, Hu Y, Wang G, et al. Inhibition of HMGB1 release via salvianolic acid B-mediated SIRT1 up-regulation protects rats against non-alcoholic fatty liver disease. Sci Rep. 2015; 5: 16013.

127. Zhang N, Hu Y, Ding C, Zeng W, Shan W, Fan H, et al. Salvianolic acid B protects against chronic alcoholic liver injury via SIRT1-mediated inhibition of CRP and ChREBP in rats. Toxicol Lett. 2016; 267: 1-10.

128. Ying HZ, Liu YH, Yu B, Wang ZY, Zang JN, Yu CH. Dietary quercetin ameliorates nonalcoholic steatohepatitis induced by a high-fat diet in gerbils. Food Chem Toxicol. 2013; 52: 53-60.
129. Beher D, Wu J, Cumine S, Kim KW, Lu SC, Atangan L, et al. Resveratrol is not a direct activator of SIRT1 enzyme activity. Chem Biol Drug Des. 2009; 74: 619-24.

130. Walle T. Bioavailability of resveratrol. Ann N Y Acad Sci. 2011; 1215: 9-15.

131. Walle T, Hsieh F, DeLegge MH, Oatis JE, Jr., Walle UK. High absorption but very low bioavailability of oral resveratrol in humans. Drug Metab Dispos. 2004; 32: 1377-82.

132. Milne JC, Lambert PD, Schenk S, Carney DP, Smith JJ, Gagne DJ, et al. Small molecule activators of SIRT1 as therapeutics for the treatment of type 2 diabetes. Nature. 2007; 450: 712-6.

133. Yamazaki Y, Usui I, Kanatani Y, Matsuya Y, Tsuneyama K, Fujisaka S, et al. Treatment with SRT1720, a SIRT1 activator, ameliorates fatty liver with reduced expression of lipogenic enzymes in MSG mice. Am J Physiol Endocrinol Metab. 2009; 297: E1179-86.

134. Li Y, Wong K, Giles A, Jiang J, Lee JW, Adams AC, et al. Hepatic SIRT1 attenuates hepatic steatosis and controls energy balance in mice by inducing fibroblast growth factor 21. Gastroenterology. 2014; 146: 539-49

135. Mukhopadhyay P, Horvath B, Rajesh M, Varga ZV, Gariani K, Ryu D, et al. PARP inhibition protects against alcoholic and non-alcoholic steatohepatitis. J Hepatol. 2017; 66: 589-600.

136. Gariani K, Ryu D, Menzies KJ, Yi HS, Stein S, Zhang H, et al. Inhibiting poly ADP-ribosylation increases fatty acid oxidation and protects against fatty liver disease. J Hepatol. 2017; 66: 132-41.

137. Huang K, Du M, Tan X, Yang L, Li X, Jiang Y, et al. PARP1-mediated PPARalpha poly(ADP-ribosyl)ation suppresses fatty acid oxidation in non-alcoholic fatty liver disease. J Hepatol. 2016: doi: 10.1016/j.jhep.2016.11.020

138. Zhang $\mathrm{Y}$, Wang $\mathrm{C}$, Tian $\mathrm{Y}$, Zhang $\mathrm{F}, \mathrm{Xu} \mathrm{W}$, Li X, et al. Inhibition of Poly(ADP-Ribose) Polymerase-1 Protects Chronic Alcoholic Liver Injury. Am J Pathol. 2016; 186: 3117-30.

139. Bai P, Canto C, Oudart H, Brunyanszki A, Cen YN, Thomas C, et al. PARP-1 Inhibition Increases Mitochondrial Metabolism through SIRT1 Activation. Cell metabolism. 2011; 13: 461-8

140. Faghihzadeh F, Adibi P, Rafiei R, Hekmatdoost A. Resveratrol supplementation improves inflammatory biomarkers in patients with nonalcoholic fatty liver disease. Nutr Res. 2014; 34: 837-43

141. Faghihzadeh F, Adibi P, Hekmatdoost A. The effects of resveratrol supplementation on cardiovascular risk factors in patients with non-alcoholic fatty liver disease: a randomised, double-blind, placebo-controlled study. Br J Nutr. 2015; 114: 796-803.

142. Chen S, Zhao X, Ran L, Wan J, Wang X, Oin Y, et al. Resveratrol improves insulin resistance, glucose and lipid metabolism in patients with non-alcoholic fatty liver disease: a randomized controlled trial. Dig Liver Dis. 2015; 47: 226-32.

143. Heeboll S, Kreuzfeldt M, Hamilton-Dutoit S, Kjaer Poulsen M, Stodkilde-Jorgensen $\mathrm{H}$, Moller $\mathrm{HJ}$, et al. Placebo-controlled, randomised clinical trial: high-dose resveratrol treatment for non-alcoholic fatty liver disease. Scand J Gastroenterol. 2016; 51: 456-64.

144. Chachay VS, Macdonald GA, Martin JH, Whitehead JP, O'Moore-Sullivan TM, Lee $\mathrm{P}$, et al. Resveratrol does not benefit patients with nonalcoholic fatty liver disease. Clin Gastroenterol Hepatol. 2014; 12: 2092-103 e1-6.

145. Picard F, Kurtev M, Chung N, Topark-Ngarm A, Senawong T, Machado De Oliveira R, et al. Sirt1 promotes fat mobilization in white adipocytes by repressing PPAR-gamma. Nature. 2004; 429: 771-6.

146. Chakrabarti P, English T, Karki S, Qiang L, Tao R, Kim J, et al. SIRT1 controls lipolysis in adipocytes via FOXO1-mediated expression of ATGL. J Lipid Res. 2011; 52: 1693-701.

147. Xu C, Bai B, Fan P, Cai Y, Huang B, Law IK, et al. Selective overexpression of human SIRT1 in adipose tissue enhances energy homeostasis and prevents the deterioration of insulin sensitivity with ageing in mice. Am J Transl Res. 2013; 5: 412-26.

148. Chen J, Zhang B, Wong N, Lo AWI, To KF, Chan AWH. Sirtuin 1 Is Upregulated in a Subset of Hepatocellular Carcinomas where It Is Essential for Telomere Maintenance and Tumor Cell Growth (vol 71, pg 4138, 2011). Cancer Res. 2012; 72: 1038-

149. Portmann S, Fahrner R, Lechleiter A, Keogh A, Overney S, Laemmle A, et al. Antitumor Effect of SIRT1 Inhibition in Human HCC Tumor Models In Vitro and In Vivo. Mol Cancer Ther. 2013; 12: 499-508.

150. Chen HC, Jeng YM, Yuan RH, Hsu HC, Chen YL. SIRT1 Promotes Tumorigenesis and Resistance to Chemotherapy in Hepatocellular Carcinoma and its Expression Predicts Poor Prognosis. Ann Surg Oncol. 2012; 19: 2011-9.

151. Wang RH, Sengupta K, Li C, Kim HS, Cao L, Xiao C, et al. Impaired DNA damage response, genome instability, and tumorigenesis in SIRT1 mutant mice. Cancer Cell. 2008; 14: 312-23.

152. Rajasekaran D, Elavarasan J, Sivalingam M, Ganapathy E, Kumar A, Kalpana $\mathrm{K}$, et al. Resveratrol interferes with N-nitrosodiethylamine-induced hepatocellular carcinoma at early and advanced stages in male Wistar rats. Mol Med Report. 2011; 4: 1211-7.

153. Park S, Lim J, Kim JR, Cho S. Inhibitory effects of resveratrol on hepatitis B virus X-protein (HBx)-induced hepatocellular carcinoma (HCC). J Vet Sci. 2017.

154. Gao F, Deng G, Liu W, Zhou K, Li M. Resveratrol suppresses human hepatocellular carcinoma via targeting HGF-c-Met signaling pathway. Oncol Rep. 2017; 37: 1203-11. 
155. Zhang XL, Yu H, Xiong YY, Ma ST, Zhao L, She SF. Resveratrol down-regulates Myosin light chain kinase, induces apoptosis and inhibits diethylnitrosamine-induced liver tumorigenesis in rats. Int J Mol Sci. 2013; 14: 1940-51.

156. Mayoral R, Osborn O, McNelis J, Johnson AM, Oh DY, Izquierdo CL, et al. Adipocyte SIRT1 knockout promotes PPARgamma activity, adipogenesis and insulin sensitivity in chronic-HFD and obesity. Mol Metab. 2015; 4: 378-91.

157. Ka SO, Song MY, Bae EJ, Park BH. Myeloid SIRT1 regulates macrophage infiltration and insulin sensitivity in mice fed a high-fat diet. J Endocrinol. 2015; 224: 109-18.

158. Kim KE, Kim H, Heo RW, Shin HJ, Yi CO, Lee DH, et al. Myeloid-specific SIRT1 Deletion Aggravates Hepatic Inflammation and Steatosis in High-fat Diet-fed Mice. Korean J Physiol Pharmacol. 2015; 19: 451-60.

159. Szkudelska K, Deniziak M, Ros P, Gwozdz K, Szkudelski T. Resveratrol alleviates ethanol-induced hormonal and metabolic disturbances in the rat. Physiol Res. 2017; 66: 135-45.

160. Yang Y, Li W, Liu Y, Sun Y, Li Y, Yao Q, et al. Alpha-lipoic acid improves high-fat diet-induced hepatic steatosis by modulating the transcription factors SREBP-1, FoxO1 and Nrf2 via the SIRT1/LKB1/AMPK pathway. J Nutr Biochem. 2014; 25: 1207-17.

161. Chen WL, Kang CH, Wang SG, Lee HM. alpha-Lipoic acid regulates lipid metabolism through induction of sirtuin 1 (SIRT1) and activation of AMP-activated protein kinase. Diabetologia. 2012; 55: 1824-35.

162. Chung J, Koo K, Lian FZ, Hu KQ, Ernst H, Wang XD. Apo-10 '-Lycopenoic Acid, a Lycopene Metabolite, Increases Sirtuin $1 \mathrm{mRNA}$ and Protein Levels and Decreases Hepatic Fat Accumulation in ob/ob Mice. J Nutr. 2012; 142: 405-10.

163. Castano D, Larequi E, Belza I, Astudillo AM, Martinez-Anso E, Balsinde J, et al. Cardiotrophin-1 eliminates hepatic steatosis in obese mice by mechanisms involving AMPK activation. J Hepatol. 2014; 60: 1017-25.

164. Liu X, Gao Y, Li M, Geng C, Xu H, Yang Y, et al. Sirt1 mediates the effect of the heme oxygenase inducer, cobalt protoporphyrin, on ameliorating liver metabolic damage caused by a high-fat diet. J Hepatol. 2015; 63: 713-21.

165. Sodhi K, Puri N, Favero G, Stevens S, Meadows C, Abraham NG, et al. Fructose Mediated Non-Alcoholic Fatty Liver Is Attenuated by HO-1-SIRT1 Module in Murine Hepatocytes and Mice Fed a High Fructose Diet. PLoS One. 2015; 10: e0128648.

166. Lee J, Hong SW, Chae SW, Kim DH, Choi JH, Bae JC, et al. Exendin-4 Improves Steatohepatitis by Increasing Sirt1 Expression in High-Fat Diet-Induced Obese C57BL/6J Mice. PLoS One. 2012; 7: e31394.

167. Lee J, Hong SW, Park SE, Rhee EJ, Park CY, Oh KW, et al. Exendin-4 regulates lipid metabolism and fibroblast growth factor 21 in hepatic steatosis. Metab Clin Exp. 2014; 63: 1041-8.

168. Choi Y, Yanagawa Y, Kim S, Park T. Involvement of SIRT1-AMPK signaling in the protective action of indole-3-carbinol against hepatic steatosis in mice fed a high-fat diet. J Nutr Biochem. 2013; 24: 1393-400.

169. Valdecantos MP, Perez-Matute P, Gonzalez-Muniesa P, Prieto-Hontoria PL, Moreno-Aliaga MJ, Martinez JA. Lipoic Acid Improves Mitochondrial Function in Nonalcoholic Steatosis Through the Stimulation of Sirtuin 1 and Sirtuin 3. Obesity. 2012; 20: 1974-83.

170. Shin SY, Kim TH, Wu H, Choi YH, Kim SG. SIRT1 activation by methylene blue, a repurposed drug, leads to AMPK-mediated inhibition of steatosis and steatohepatitis. Eur J Pharmacol. 2014; 727: 115-24.

171. Hong S, Moreno-Navarrete JM, Wei X, Kikukawa Y, Tzameli I, Prasad D, et al. Nicotinamide $\mathrm{N}$-methyltransferase regulates hepatic nutrient metabolism through Sirt1 protein stabilization. Nat Med. 2015; 21: 887-94.

172. Zhou CC, Yang X, Hua X, Liu J, Fan MB, Li GQ, et al. Hepatic NAD (+) deficiency as a therapeutic target for non-alcoholic fatty liver disease in ageing. Br J Pharmacol. 2016; 173: 2352-68.

173. Derdak Z, Villegas KA, Harb R, Wu AM, Sousa A, Wands JR. Inhibition of p53 attenuates steatosis and liver injury in a mouse model of non-alcoholic fatty liver disease. J Hepatol. 2013; 58: 785-91.

174. Park EJ, Kim YM, Kim HJ, Jang SY, Oh MH, Lee DH, et al. (S)YS-51, a novel isoquinoline alkaloid, attenuates obesity-associated non-alcoholic fatty liver disease in mice by suppressing lipogenesis, inflammation and coagulation. Eur J Pharmacol. 2016; 788: 200-9.

175. Zhang ZF, Fan SH, Zheng YL, Lu J, Wu DM, Shan Q, et al. Troxerutin improves hepatic lipid homeostasis by restoring $\mathrm{NAD}(+)$-depletion-mediated dysfunction of lipin 1 signaling in high-fat diet-treated mice. Biochem Pharmacol. 2014; 91: 74-86.

176. Mandal S, Mukhopadhyay S, Bandhopadhyay S, Sen G, Biswas T. 14-Deoxyandrographolide alleviates ethanol-induced hepatosteatosis through stimulation of AMP-activated protein kinase activity in rats. Alcohol. 2014; 48: 123-32.

177. Zhang $\mathrm{P}$, Qiang $\mathrm{X}$, Zhang $\mathrm{M}$, Ma D, Zhao $Z$, Zhou $C$, et al. Demethyleneberberine, a natural mitochondria-targeted antioxidant, inhibits mitochondrial dysfunction, oxidative stress, and steatosis in alcoholic liver disease mouse model. J Pharmacol Exp Ther. 2015; 352: 139-47.

178. Shen $\mathrm{Z}$, Liang $\mathrm{XM}$, Rogers $\mathrm{CQ}$, Rideout $\mathrm{D}$, You $\mathrm{M}$. Involvement of adiponectin-SIRT1-AMPK signaling in the protective action of rosiglitazone against alcoholic fatty liver in mice. Am J Physiol Gastrointest Liver Physiol. 2010; 298: G364-G74. 